\title{
Observations of cloud microphysics and ice formation during COPE
}

\author{
J. W. Taylor ${ }^{1}$, T. W. Choularton ${ }^{1}$, A. M. Blyth ${ }^{2}$, Z. Liu ${ }^{1}$, K. N. Bower ${ }^{1}$, J. Crosier ${ }^{1,3}$, M. W. Gallagher ${ }^{1}$, \\ P. I. Williams ${ }^{1,3}$, J. R. Dorsey ${ }^{1,3}$, M. J. Flynn ${ }^{1}$, L. J. Bennett ${ }^{2}$, Y. Huang ${ }^{2}$, J. French ${ }^{4}$, A. Korolev ${ }^{5}$, and P. R. A. Brown \\ ${ }^{1}$ Centre for Atmospheric Science, School of Earth, Atmospheric and Environmental Sciences, \\ University of Manchester, Manchester, UK \\ ${ }^{2}$ National Centre for Atmospheric Science, University of Leeds, Leeds, UK \\ ${ }^{3}$ National Centre for Atmospheric Science, University of Manchester, Manchester, UK \\ ${ }^{4}$ Department of Atmospheric Science, University of Wyoming, Laramie, Wyoming, USA \\ ${ }^{5}$ Cloud Physics and Severe Weather Research Section, Environment Canada, Toronto, Ontario, Canada \\ ${ }^{6}$ Met Office, Exeter, Devon, UK
}

Correspondence to: J. W. Taylor (jonathan.taylor@manchester.ac.uk)

Received: 20 May 2015 - Published in Atmos. Chem. Phys. Discuss.: 15 June 2015

Revised: 8 December 2015 - Accepted: 29 December 2015 - Published: 25 January 2016

\begin{abstract}
We present microphysical observations of cumulus clouds measured over the southwest peninsula of the UK during the COnvective Precipitation Experiment (COPE) in August 2013, which are framed into a wider context using ground-based and airborne radar measurements. Two lines of cumulus clouds formed in the early afternoon along convergence lines aligned with the peninsula. The lines became longer and broader during the afternoon due to new cell formation and stratiform regions forming downwind of the convective cells. Ice concentrations up to $350 \mathrm{~L}^{-1}$, well in excess of the expected ice nuclei (IN) concentrations, were measured in the mature stratiform regions, suggesting that secondary ice production was active.

Detailed sampling focused on an isolated liquid cloud that glaciated as it matured to merge with a band of cloud downwind. In the initial cell, drizzle concentrations increased from $\sim 0.5$ to $\sim 20 \mathrm{~L}^{-1}$ in around $20 \mathrm{~min}$. Ice concentrations developed up to a few per litre, which is around the level expected of primary IN. The ice images were most consistent with freezing drizzle, rather than smaller cloud drops or interstitial IN forming the first ice.

As new cells emerged in and around the cloud, ice concentrations up to 2 orders of magnitude higher than the predicted IN concentrations developed, and the cloud glaciated over a period of $12-15 \mathrm{~min}$. Almost all of the first ice particles to be observed were frozen drops, while vapour-grown ice crystals were dominant in the latter stages. Our observations are consistent with the production of large numbers
\end{abstract}

of small secondary ice crystals/fragments, by a mechanism such as Hallett-Mossop or droplets shattering upon freezing. Some of the small ice froze drizzle drops on contact, while others grew more slowly by vapour deposition. Graupel and columns were seen in cloud penetrations up to the $-12{ }^{\circ} \mathrm{C}$ level, though many ice particles were mixed habit due to riming and growth by vapour deposition at multiple temperatures.

Our observations demonstrate that the freezing of drizzle/raindrops is an important process that dominates the formation of large ice in the intermediate stages of cloud development. As these frozen drops were the first precipitation observed, interactions between the warm-rain and secondary ice production processes appear to be key to determining the timing and location of precipitation.

\section{Introduction}

Extreme rainfall by isolated convective storms can cause flash flooding, leading to property damage and possible loss of life. Short-lived convective storms are thought to be responsible for over half of flash flooding events in the UK (Hand et al., 2004), and over 3 million properties in England are thought to be at risk to surface flooding (Environment Agency, 2009). The southwest peninsula of the UK has a long history of summer flash flooding, with dozens of incidents reported in the last century (Cornwall Council, 2011). 
The steep, narrow valleys on the north coast of the southwest peninsula are particularly vulnerable to flooding as they funnel rainfall down to the sea.

During periods of southwesterly winds, the airstream aligns with the peninsula, and the combination of surface friction and onshore heating drive moist sea breeze fronts inland from both the north and south coasts (Warren et al., 2014). The convergence associated with these opposing fronts creates conditions favourable for convective cloud formation. Similar meteorological phenomena may be found on long, thin peninsulas such as Florida (Burpee, 1979) and the Italian Salento peninsula (Mangia et al., 2004).

In August 2004, particularly destructive flash flooding caused severe damage to the village of Boscastle, and several other villages nearby were also badly affected. A series of convective cells aligned with the southwesterly wind to form a narrow, quasistationary band of precipitation, and up to $200 \mathrm{~mm}$ of rain fell on the surrounding area in around $4 \mathrm{~h}$ (Golding, 2005; Golding et al., 2005). Other notable examples of extreme flash flooding in the area include the "Great Flood" of July 1847, which destroyed several bridges on the River Camel, the Lynmouth flood of 1952, which took 34 lives, and the June 1957 floods in which $200 \mathrm{~mm}$ of rain fell in just a few hours.

At the time of the August 2004 floods, the UK Met Office's forecast model grid spacing was $12 \mathrm{~km}$, which was insufficient to resolve the convective cells that formed near Boscastle. The model grid spacing has since been improved to a $1.5 \mathrm{~km}$ grid, and higher-resolution hindcasts are able to resolve the August 2004 storms (Golding, 2005). However, quantitative precipitation forecasts remain challenging.

Forecasting accuracy is dependent on the successful prediction of the onset, duration, location(s), and intensity of precipitation, which involves a physically realistic representation of many interacting physical processes. Microphysical processes alone are subject to significant uncertainty. Cloudresolving models must use parameterisations to predict interactions between different sizes of cloud drops and different types of ice/snow. The use of different microphysical schemes in cloud-resolving models can affect the location, phase, and intensity of precipitation (e.g. Loftus and Cotton, 2014; Dasari and Salgado, 2015).

While recent progress has been made in understanding the initiation and development of convective clouds (Browning et al., 2007), and exploring model biases and limitations at different resolutions (Stein et al., 2015), gaining a more detailed understanding of the microphysical processes involved remains a key aspect of improving quantitative precipitation forecasting. Huang et al. (2008) found that in a small sample of clouds formed in similar circumstances, the dominant mechanism leading to the formation of precipitationsized particles was the accretional growth of graupel. Supercooled raindrops formed by the warm-rain process are thought to play an important role in short-circuiting the formation of graupel, hence allowing the more rapid initiation of the Hallett-Mossop (H-M) ice multiplication process (Hallett and Mossop, 1974; Chisnell and Latham, 1976; Phillips et al., 2001; Huang et al., 2008; Sun et al., 2010; Crawford et al., 2012). Several studies have observed such drops in the early stages of convective clouds (e.g. Koenig, 1963; Blyth and Latham, 1993; Rangno and Hobbs, 2005; Lawson et al., 2015), particularly in environments with a warmer cloud base. It is not clear if the supercooled raindrops are the first particles to freeze, or if they collide with primary ice particles produced from frozen cloud drops (e.g. Phillips et al., 2001). On a per-particle basis, larger drops formed by collision-coalescence are more likely to contain ice nuclei (IN) than smaller drops, but they are generally much fewer in number.

Raindrops encountering ice splinters ejected by the H-M process can also freeze to become instant rimers, meaning the $\mathrm{H}-\mathrm{M}$ process can progress more quickly than if the splinters had to grow to sizes where they can rime by vapour deposition alone (Chisnell and Latham, 1976). Crawford et al. (2012) found that, by this process, drizzle drops played an important role in the rapid glaciation of shallow convective clouds. However, Lawson et al. (2015) recently suggested that in cumulus with very active warm-rain processes, fragmentation of freezing drops can also lead to cascading secondary ice production, in the absence of $\mathrm{H}-\mathrm{M}$.

In this paper, we present observations taken during the COnvective Precipitation Experiment (COPE), which was conducted in the southwest peninsula of the UK during July and August 2013 (Blyth et al., 2015; Leon et al., 2015). Measurements of the microphysics, dynamics, and thermodynamics were made by two research aircraft, a ground-based precipitation radar, a suite of aerosol instruments, and other instrumentation. The principle objective was to document the microphysical observations in sufficient detail to be able to make inferences about the processes occurring in the sampled clouds. This will enable the observations to be used in future work to evaluate the performance of high-resolution numerical models of the clouds and, in particular, the relative importance of resolution and parameterised microphysics in achieving quantitative precipitation forecasts.

First, we examine the horizontal structure and phase of a line of cumulus oriented along the wind direction, formed in similar meteorological conditions to the August 2004 floods. We then present detailed measurements of the development of an initially isolated cloud as it glaciated. Multiple aircraft penetrations were made through this cloud at increasing altitude as it grew in height, and we present observations showing the conversion of supercooled drizzle drops to graupel. We demonstrate a progression from liquid to ice cloud through mixed-phase stages involving primary graupel, secondary graupel, columns, and mixed-habit ice particles. Compared to previous studies, the use of newer instrumentation with more reliable detection of smaller ice particles (Lawson et al., 2006) means we were better able to 
detect ice closer to where it was produced, and hence may better deduce information on its origins.

\section{Experimental}

\subsection{The COPE project}

COPE took place in the southwest peninsula of the UK during July-August 2013, and the analysis presented here focuses on one case study from 3 August, as it presented the most detailed set of observations, including repeated aircraft penetrations through cloud regions with prolific ice production. In situ measurements during COPE were performed using two aircraft platforms: the UK Facility for Airborne Atmospheric Measurement BAe-146 and University of Wyoming King Air 200T (UWKA). Ground-based measurements were performed using the UK National Centre for Atmospheric Science (NCAS) mobile precipitation radar in Davidstow, and an additional site located nearby hosted aerosol instrumentation, which was running throughout the whole of the campaign.

The BAe-146 and UWKA aircraft each hosted a suite of in situ probes, providing measurements of size-resolved cloud particle number concentration (and to some extent shape) across the entire size range of interest (3-6200 $\mu \mathrm{m})$. The UWKA was also equipped with a Doppler cloud radar, which provided high-resolution vertical profiles mapping the structure of cloud directly above and below the aircraft. The sampling strategy involved the UWKA flying in and around cloud tops, while the BAe-146 sampled clouds and aerosols at lower levels. The ground-based precipitation radar had a lower spatial resolution than the UWKA cloud radar, but covered a much wider area, and provides the best measure of the horizontal extent and temporal evolution of the clouds.

Both aircraft were fitted with a suite of instrumentation to measure standard data products such as position and velocity, as well as meteorological variables including temperature, pressure, dew point, and liquid water content (LWC). A full summary of instrumentation deployed during COPE is provided by Leon et al. (2015). Here we summarise only the instrumentation used in this analysis.

\subsection{BAe-146 instrumentation}

\subsubsection{Meteorological instrumentation}

Ambient air temperature was monitored using de-iced and non-de-iced Rosemount 102 sensors, and here we use the deiced measurement as most of the measurements were taken at sub-zero temperatures. When passing through dense liquid cloud, these sensors are known to underestimate temperature by up to a few degrees Celsius due to wetting (Lawson and Cooper, 1990), so we use the out-of-cloud temperature at the same altitude to estimate cloud temperatures. In parts of the cloud that are not at their level of neutral buoyancy, the in-cloud temperatures may be up to a few degrees Celsius warmer or cooler due to the energies associated with changes in the phase of water molecules (Wang and Geerts, 2009). A de-iced Aventech aircraft-integrated meteorological measurement system (AIMMS)-20 turbulence probe (Beswick et al., 2008) was used to measure the 3-D wind vector at $20 \mathrm{~Hz}$. The stated accuracy of the AIMMS vertical wind $(W)$ is $\sim 0.75 \mathrm{~m} \mathrm{~s}^{-1}$, though intercomparisons between the AIMMS and the BAe-146's radome-mounted five-port turbulence sensor agreed within around $0.5 \mathrm{~m} \mathrm{~s}^{-1}$.

\subsubsection{Cloud instrumentation}

Cloud droplets with diameter $3 \leq D_{P}<50 \mu \mathrm{m}$ were measured using a Droplet Measurement Technologies (DMT) cloud droplet probe (CDP; Lance, 2012). The CDP was calibrated several times during the campaign using glass beads (Rosenberg et al., 2012), and the sample area was measured to be $0.517 \mathrm{~mm}^{2}$ using the droplet gun method (Lance et al., 2010). For more reliable sizing, bins $4-7$ and $8-11$ (6.1-8.1 and 7.6-12.6 $\mu \mathrm{m}$ in diameter) were combined to minimise the effect of Mie sizing ambiguities, which caused systematic spikes in the size distributions. LWC was calculated by integrating the CDP size distribution and, on the flight discussed in this analysis, the values generated this way agreed with the on-board Johnson-Williams hotwire probe within $\sim 12 \%$ below $\sim 0.9 \mathrm{~g} \mathrm{~m}^{-3}$ (on the CDP), above which the hotwire probe began to saturate. The reported LWC values are from the CDP, as the hotwire probe suffered from wetting and saturation artefacts.

Larger cloud particles were measured using a Stratton Park Engineering Company (SPEC) 2DS stereo probe (Lawson et al., 2006) and a DMT cloud imaging probe 100 (CIP100; Baumgardner et al., 2001), which are optical array probes (OAPs) that capture the size and shape of particles by measuring the shadow they cast on a photodiode array as they pass through a laser. The 2DS has a nominal size range of $10-1280 \mu \mathrm{m}$, with a resolution of $10 \mu \mathrm{m}$. The CIP100 captures larger particles but in less detail, with a nominal size range of $100-6400 \mu \mathrm{m}$ and $100 \mu \mathrm{m}$ resolution. All the OAPs were fitted with anti-shatter tips to reduce shattering artefacts (Korolev et al., 2011). A comparison of example size distributions measured by the three probes is presented in Fig. 1, which shows broad agreement between the probes where their size ranges overlap.

The CDP, 2DS, and CIP100 all use the measured true airspeed from the on-board five-hole turbulence probe to calculate sample volume. A comparison of the turbulence probe airspeed to that derived from the AIMMS probe showed both measurements were consistent within $\pm 2 \%$. Since the AIMMS is located in a similar underwing location to the particle probes, this gives confidence in their calculated sample volumes. A description of the 2DS image analysis is provided in Appendix A1. Additionally, we use the method described by Harris-Hobbs and Cooper (1987) to calculate the 

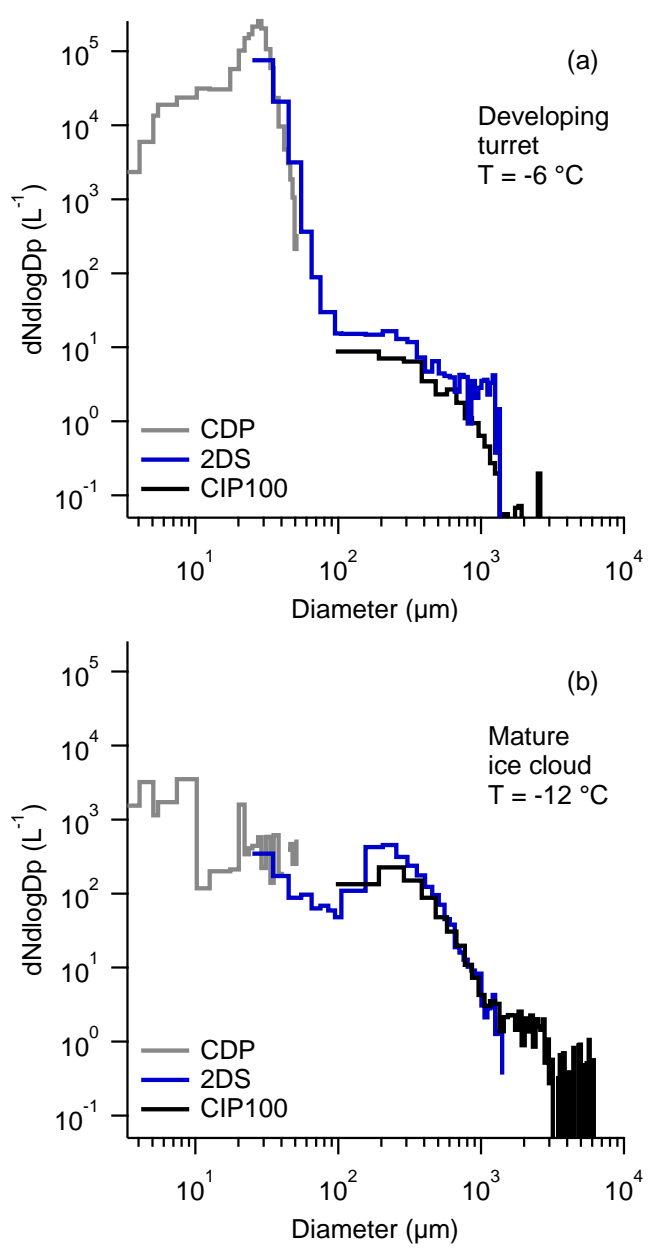

Figure 1. Comparison of size distributions from the CDP, 2DS, and CIP100 probes during selected cloud penetrations through (a) a developing turret and (b) a mature glaciated region. The first two size bins from the 2DS and CIP100 were removed, as they are subject to larger uncertainty, and are not used in this analysis.

ice production rate $\left(P_{0}\right)$ in regions where columns formed the majority of ice crystals. Further details of this calculation are given in Appendix A2.

Additional images of hydrometeors were obtained using a SPEC cloud particle imager (CPI; Connolly et al., 2007). Unlike the OAP probes, which utilise 1-D detector arrays, the CPI uses a 2-D charge-coupled device (CCD) camera, which results in greatly enhanced image quality (8-bit greyscale images, $2.3 \mu \mathrm{m}$ pixel size). Quantitative hydrometeor concentrations could not be determined from the CPI during COPE, but the images collected provide further insight into the shape of the hydrometeors encountered. The CPI images shown in this manuscript have been processed by increasing the brightness by $40 \%$ and contrast by $20 \%$ to clarify the images.

\subsubsection{Aerosol instrumentation}

Total aerosol number concentration for sizes larger than $2.5 \mathrm{~nm}$ was measured using an Aerosol Dynamics Inc. model 3786-LP water-filled condensation particle counter (WCPC; Hering et al., 2005), based on the TSI model 3786 modified for use at low pressure. The aerosol size distribution was measured with a wing-mounted Particle Measurement Systems passive cavity aerosol spectrometer probe 100X (PCASP), with electronics upgraded by DMT, which was calibrated as detailed by Rosenberg et al. (2012). The PCASP measures the dry optical size of particles $0.1-3 \mu \mathrm{m}$ in diameter. Out of cloud, the CDP can also be used to detect aerosol $>3 \mu \mathrm{m}$ optical diameter, though this measurement is performed at ambient humidity, whereas the other aerosol probes use dried airflows.

The aerosol composition was sampled with an Aerodyne Research Inc. compact time-of-flight aerosol mass spectrometer (AMS; Drewnick et al., 2005; Canagaratna et al., 2007), which reports submicron nonrefractory organic aerosol (OA), sulfate $\left(\mathrm{SO}_{4}^{2-}\right)$, nitrate $\left(\mathrm{NO}_{3}^{-}\right)$, ammonium $\left(\mathrm{NH}_{4}^{+}\right)$, and non-sea salt chloride $\left(\mathrm{Chl}_{\mathrm{NSS}}^{-}\right)$. Refractory black carbon (BC) concentrations were also measured using a DMT single-particle soot photometer (SP2; Stephens et al., 2003; Schwarz et al., 2010), with optics and electronics upgraded to be functionally identical to the current SP2 model D. The SP2 was calibrated with Aquadag as recommended by Baumgardner et al. (2012) and Laborde et al. (2012). Further details on the aerosol instrumentation and measurements will be provided in a future manuscript.

\subsection{UWKA instrumentation}

The UWKA measured cloud drops $2-50 \mu \mathrm{m}$ in diameter using a DMT CDP calibrated by the manufacturer. Larger cloud particles were imaged using a DMT CIP-25GS (CIP25 hereafter) and Particle Measuring Systems 2DP probes, which are OAP probes with nominal diameters $25-1600 \mu \mathrm{m}$ and $200-$ $6400 \mu \mathrm{m}$, respectively. Habit classification was performed on the CIP25 data, as described by Korolev and Sussman (2000). This analysis outputs the fraction of particles with $>20$ pixels that are classed as spheres, irregulars, needles, or dendrites. The 20-pixel threshold typically corresponds to a diameter of $\sim 125 \mu \mathrm{m}$ for particles with an axial ratio of order 1.

The Wyoming Cloud Radar (WCR; Wang et al., 2012) is a $95 \mathrm{GHz}$ Doppler radar with beams pointing vertically up and down (relative to the pitch and roll of the aircraft) and down-forward, though only the vertical data are discussed here. The along track (horizontal) and along beam (vertical) resolutions were approximately 6 and $30 \mathrm{~m}$, respectively, for a nominal airspeed of $100 \mathrm{~m} \mathrm{~s}^{-1}$ and $16 \mathrm{~Hz}$ sampling frequency. The WCR measured reflectivity and Doppler velocity, which is a convolution of particle fall speed and the vertical wind velocity. When precipitation-sized particles are 
present they tend to dominate the reflectivity, leading to Doppler velocities considerably lower than the vertical air velocity. Data $<3$ standard deviations of the measured noise were removed to clarify the images while having a minimal effect on the measured cloud data. Data were also removed when the UWKA was flying $>10^{\circ}$ from horizontal (i.e. the vertical radar beams were not pointing to the zenith and nadir). The UWKA was also fitted with a downwardpointing lidar, described by Wang et al. (2012), which was used to estimate cloud-top height during overpasses.

\subsection{NCAS precipitation radar}

The ground-based NCAS mobile precipitation radar (Blyth et al., 2015) is a dual-polarisation $9.4 \mathrm{GHz}$ Doppler radar with a $2.4 \mathrm{~m}$ diameter antenna, resulting in a $1^{\circ}$ beam width. During COPE the precipitation radar was located at Davidstow airfield $\left(50.6369^{\circ} \mathrm{N},-4.6106^{\circ} \mathrm{E}\right)$, which is near the centre of the study area. When operating, the precipitation radar performed $360^{\circ}$ plan position indicator (PPI) scans over a specified range of elevation angles. PPI scans were collected every $20 \mathrm{~s}$. During the morning and early afternoon on 3 August, barring a gap in sampling between 11:58 and 12:53 UTC, scans were performed at $1^{\circ}$ intervals centred between 0.5 and $9.5^{\circ}$ elevation. After 14:36 UTC, the scan profile was changed to $0.5-18.5^{\circ}$ elevation, at intervals of $2^{\circ}$, in order to ensure sampling of the tops of the clouds. A series of scans across the full range of elevations took $\sim 4.5 \mathrm{~min}$. The ability to obtain such a rapid sequence of multi-angle PPI scans meant that separate range-height indicator (RHI) scans of the clouds of interest were not required. The precipitation radar measured reflectivity, radial velocity and dual-polarisation parameters including differential reflectivity, specific differential phase, and co-polar cross-correlation coefficient, out to $150 \mathrm{~km}$ range with a resolution of $1^{\circ}$ and $150 \mathrm{~m}$ in the azimuthal and radial directions, respectively. We use the NCAS precipitation radar as an additional estimate of cloud-top height, as well as to show the structure of clouds during the aircraft penetrations.

\section{Results}

\subsection{Sampling overview}

The meteorological conditions on 3 August 2013 were typical of those described in Sect. 1. A low-pressure system $300 \mathrm{~km}$ northwest of northern Scotland and a weak low over the mid-Atlantic brought moist air over the southwest peninsula from the southwest. A convergence line was forecast along the peninsula, and the only weather fronts over the UK were over northwest Scotland. Figure 2 shows the vertical profile of wind speed and direction. The wind direction was southwesterly and showed little variation with altitude. The wind speed was $8-13 \mathrm{~m} \mathrm{~s}^{-1}$ up to $3 \mathrm{~km}$, then increased with height to reach $19 \mathrm{~m} \mathrm{~s}^{-1}$ by $5.8 \mathrm{~km}$.

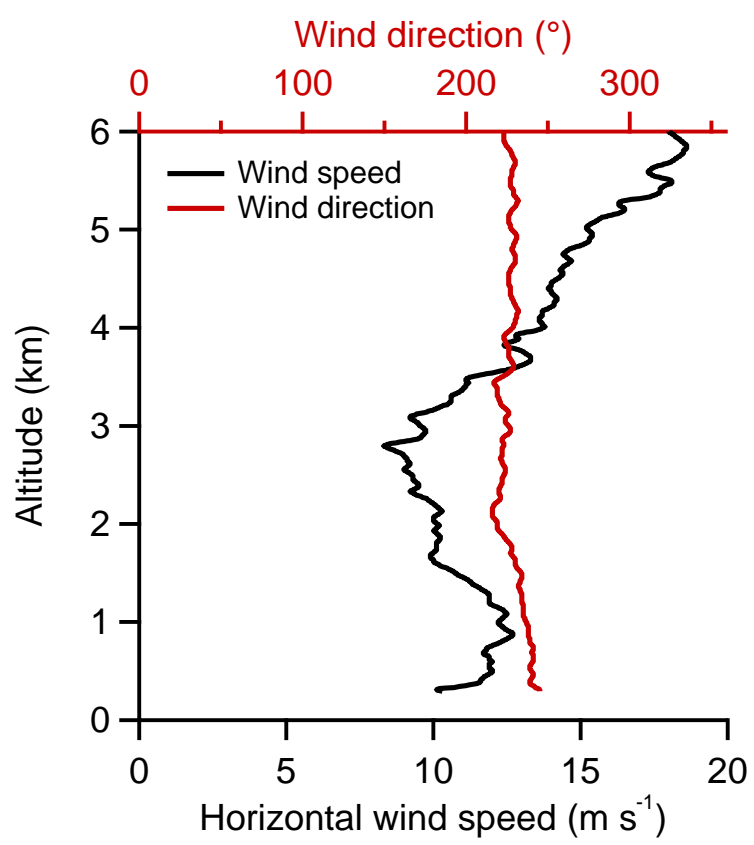

Figure 2. Vertical profile of horizontal wind speed and direction measured from the 15:00 UTC radiosonde launched from Davidstow, the same location as the NCAS precipitation radar.

Figure 3a shows the temperature and dew point from a radiosonde launched from Davidstow at 15:00 UTC. There were also launches during the measurement period at 12:00 and 13:45 UTC; however, these probes both passed through cloud on their ascent. The air was moist throughout the lower troposphere, with the RH staying above $70 \%$ up to a level of $3.5 \mathrm{~km}$ above mean sea level (hereafter, all altitudes are above mean sea level). Above this level the air became progressively drier with altitude, which would have limited clouds' ascent. There was also a weak inversion at around $\sim 5.3 \mathrm{~km}$ $\left(T \sim-15^{\circ} \mathrm{C}\right)$, which appeared to cap the tops of the highest clouds.

Figure $3 \mathrm{~b}-\mathrm{f}$ shows the vertical profile of cloud measurements made by the BAe-146 during the whole flight. Cloud base was at $\sim 1 \mathrm{~km}\left(T \sim 11^{\circ} \mathrm{C}\right)$, and the $0^{\circ} \mathrm{C}$ level was at $\sim 2.7 \mathrm{~km}$. The maximum cloud-drop number concentration measured by the $\mathrm{CDP}\left(N_{\mathrm{CDP}}\right)$ was $\sim 400 \mathrm{~cm}^{-3}$, which is not atypical for cumulus clouds, especially over land and where there are strong updrafts at cloud base. The maximum measured values of LWC approached those calculated in adiabatic parcels in the lower cloud passes, with the adiabatic fraction, $f_{\text {Ad }}$, up to 0.85 . The reader should note, however, that the values of $f_{\text {Ad }}$ in the first few hundred metres above cloud base are particularly sensitive to the cloud base altitude used to calculate the adiabatic LWC. At higher levels, $f_{\text {Ad }}$ generally decreased with altitude, probably due to a combination of precipitation scavenging, entrainment, and conversion to ice. 

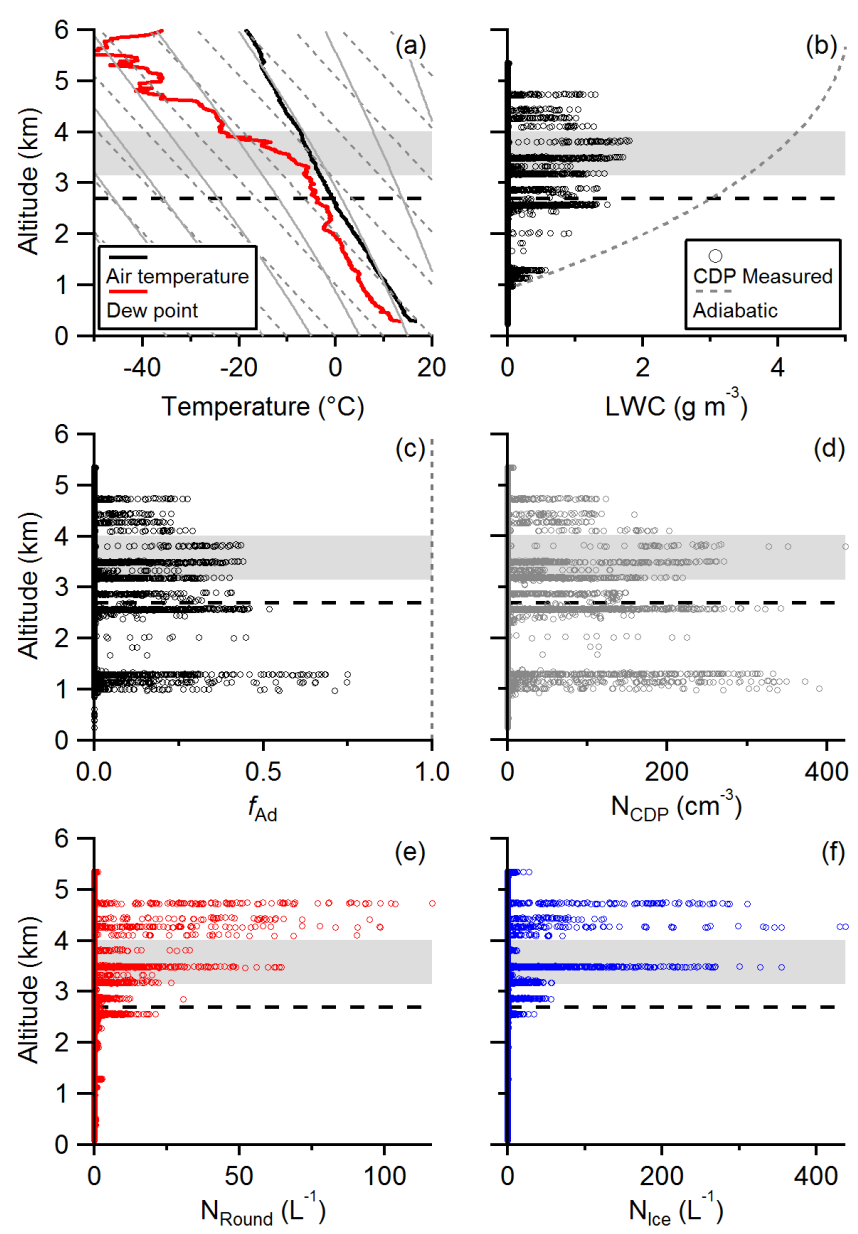

Figure 3. Vertical profile showing radiosonde data and cloud measurements made by the BAe-146. The horizontal dashed lines mark the $0{ }^{\circ} \mathrm{C}$ level, and the shaded region shows the $\mathrm{H}-\mathrm{M}$ temperature zone. Panel (a) shows temperature and dew point from the 15:00 UTC radiosonde launched from Davidstow. The solid and dashed grey lines are wet pseudo adiabats and dry adiabats, respectively. Panel (b) shows the LWC measured by the CDP, as well as the calculated adiabatic values. These data are converted to the adiabatic fraction, $f_{\text {Ad }}$ in panel (c). Panel (d) shows the droplet concentration measured by the CDP, and panels (e) and (f) show the round and ice concentrations measured by the 2DS. In this plot only, edge particles measured by the 2DS are assigned to the round category for $T \geq 0{ }^{\circ} \mathrm{C}$, and the ice category elsewhere.

The maximum number concentration of drops in the 2DS round category $\left(N_{\text {Round }}\right)$ generally increased with altitude, but the maximum concentrations of ice $\left(N_{\text {Ice }}\right)$ and $N_{\text {CDP }}$ were more variable. Ice concentrations of several hundred per litre were present in the $\mathrm{H}-\mathrm{M}$ temperature range $(-3>$ $T>-8^{\circ} \mathrm{C}$ ), but also at lower temperatures. Most of the penetrations within a few hundred metres of cloud top were at temperatures between -10 and $-12^{\circ} \mathrm{C}$, though some cloud tops reached temperatures as low as $-15^{\circ} \mathrm{C}$, which corresponds to the temperature of the inversion at $5.3 \mathrm{~km}$.
Figure 4a shows the estimated precipitation rate from the UK operational radar network (Met Office, 2003) at various points during the afternoon. Most of the clouds formed along two convergence lines running approximately southwest to northeast. Multiple cells (both isolated and interlinking) moved northeast along the lines. In Fig. 4 we define axes $\mathrm{AB}$ and $\mathrm{CD}$ along these two lines, in order to provide reference points for the rest of our analysis. Some clouds deviated off the centre line of these axes, and in some sections, cells grew large enough to interact with those from the other line. Some sections were continuous lines of cloud, with multiple cells merging with those further up/downwind as they developed. Other sections contained isolated clouds, or adjacent cells interacting where their edges met.

Figure $4 \mathrm{~b}$ and $\mathrm{c}$ show the altitude of each aircraft and sampling focus at different stages of the flight. The UWKA operated at higher altitudes compared to the BAe-146, making penetrations through cloud tops and characterising clouds from above using its downward-pointing radar. The UWKA alternated between sampling lines $\mathrm{AB}$ and $\mathrm{CD}$, making runs along and across the lines to investigate individual cells.

The BAe-146 initially performed low-level runs across and along the peninsula to characterise the boundary-layer aerosol. The average aerosol concentration and composition is summarised in Table 1 . Around $80 \%$ of the accumulationmode aerosol was ammonium sulfate, with smaller contributions from $\mathrm{OA}$ and ammonium nitrate. The small amounts of chloride detected are likely to be an underestimate, as the AMS is not able to detect sea salt. The total aerosol number concentration was $6600 \mathrm{scm}^{-3}$. The composition and low total mass loading are indicative of fairly clean marine air, but the relatively high number concentration suggests new particle formation may have occurred on the flying day. The concentration of aerosol particles larger than $0.5 \mu \mathrm{m}$ in diameter was $5 \mathrm{scm}^{-3}$. In Sect. 3.4.1 we use this concentration to estimate IN concentrations to within an order of magnitude using the parametrisation of DeMott et al. (2010).

Following the low-level aerosol runs, the BAe-146 performed a series of straight and level runs along line $\mathrm{AB}$ at altitudes of $1.3 \mathrm{~km}\left(T \sim 9{ }^{\circ} \mathrm{C}\right)$ and $2.55-2.6 \mathrm{~km}\left(T \sim 0^{\circ} \mathrm{C}\right)$. Several clouds were sampled near the southwest of the peninsula, with cloud tops generally below $3.5 \mathrm{~km}\left(T \sim-5^{\circ} \mathrm{C}\right)$, containing $0.1-0.5 \mathrm{~g} \mathrm{~m}^{-3} \mathrm{LWC}$ and ice particle number concentrations $<1 \mathrm{~L}^{-1}$. As the focus of the flight was to study ice formation, the sampling shifted to line $\mathrm{CD}$, where cloud tops grew to $>5 \mathrm{~km}$. Passes were made by the BAe- 146 at altitudes from 2.5 to $4.9 \mathrm{~km}\left(0>T>-12^{\circ} \mathrm{C}\right)$ and by the UWKA from 4.1 to $5.4 \mathrm{~km}\left(-7>T>-15^{\circ} \mathrm{C}\right)$.

The analysis in the following sections is divided up into three complementary parts, and a summary of the runs discussed is listed in Table 2. First, we use in situ and radar measurements to characterise the phase, dynamics, and spatial scales of a $40 \mathrm{~km}$ long semi-continuous section of cloud along line $\mathrm{CD}$. We then perform a similar analysis detailing the glaciation of a cloud that was initially physically sep- 

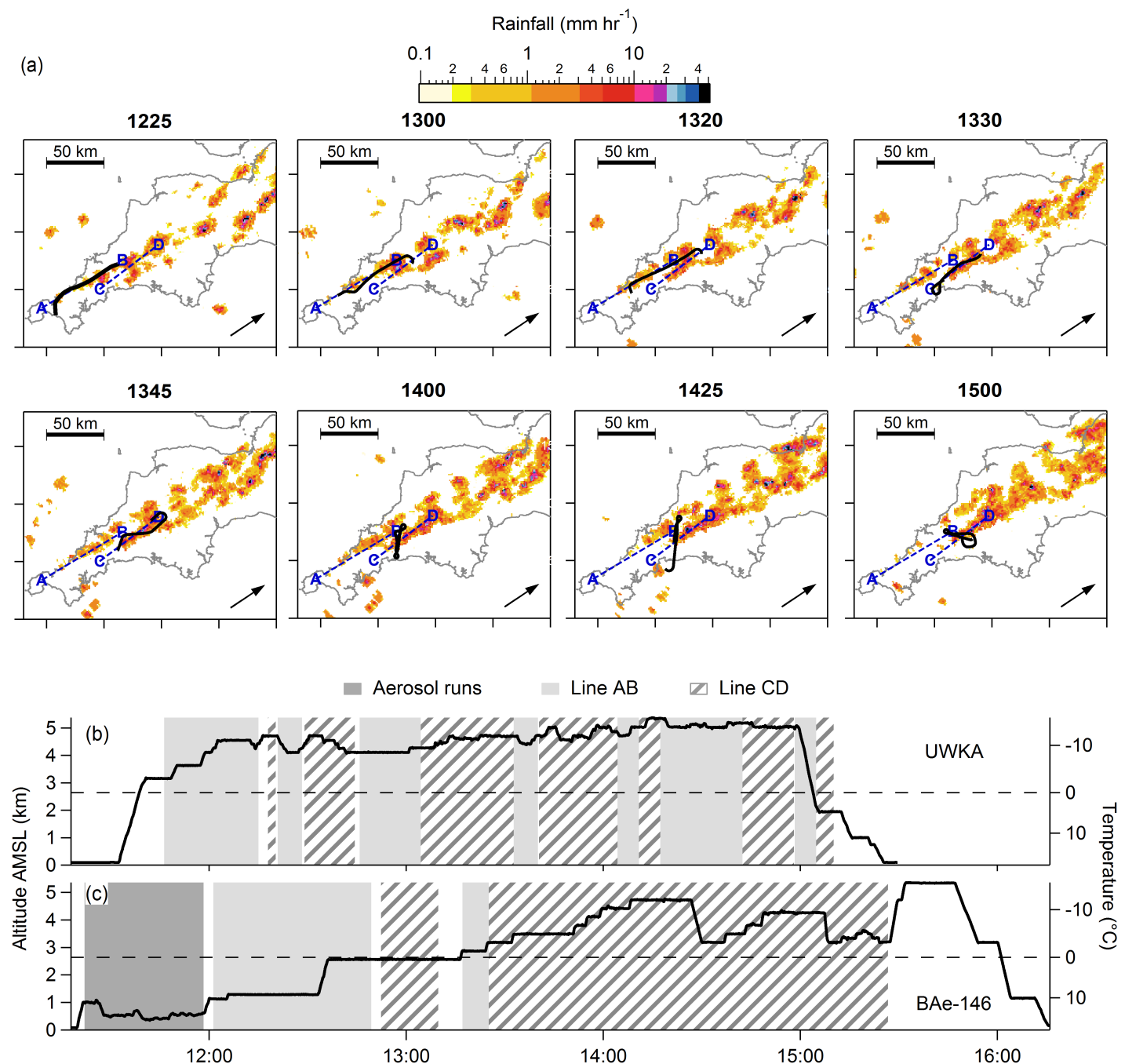

Figure 4. Overview of in situ cloud measurements made on 3 August 2014. Panel (a) shows calculated precipitation from the UK operational radar network at several points during the afternoon. The blue dashed lines are axes $\mathrm{AB}$ and $\mathrm{CD}$, and the black line is the flight track of the BAe-146 5 min either side of the time for each panel. The black arrow shows the wind direction. Panels (b) and (c) show time series of the altitude and sampling focus of the two aircraft. The listed times are in UTC, and the local time was UTC +1 .

Table 1. Mean and standard deviation of aerosol number and composition during a run along the peninsula at 570 m, between 11:52:14 and 11:58:53 UTC. The AMS chloride measurement $\left(\mathrm{Chl}_{\mathrm{NSS}}^{-}\right)$does not include sea salt, so the total chloride concentration is likely to have been higher. The s preceding the concentration units denotes that the data are corrected to standard temperature and pressure ( $273.15 \mathrm{~K}$ and $1013.25 \mathrm{hPa}$.

\begin{tabular}{lrrrl}
\hline & Mean & $\begin{array}{r}\text { Standard } \\
\text { deviation }\end{array}$ & $\begin{array}{r}\text { Number of } \\
\text { data points }\end{array}$ & Instrument \\
\hline Total aerosol conc. $\left(\mathrm{scm}^{-3}\right)$ & 6600 & 2900 & 399 & CPC \\
Aerosol $>0.5 \mu \mathrm{m}\left(\mathrm{scm}^{-3}\right)$ & 5.0 & 2.4 & 399 & PCASP/CDP \\
$\mathrm{SO}_{4}^{2-}\left(\mu \mathrm{g} \mathrm{sm}^{-3}\right)$ & 1.62 & 0.22 & 13 & AMS \\
$\mathrm{NO}_{3}^{-}\left(\mu \mathrm{g} \mathrm{sm}^{-3}\right)$ & 0.10 & 0.05 & 13 & AMS \\
$\mathrm{NH}_{4}^{+}\left(\mu \mathrm{g} \mathrm{sm}^{-3}\right)$ & 0.51 & 0.07 & 13 & AMS \\
$\mathrm{Org}^{-3}\left(\mu \mathrm{g} \mathrm{sm}^{-3}\right)$ & 0.44 & 0.10 & 13 & AMS \\
$\mathrm{Chl}_{\mathrm{NSS}}^{-}\left(\mu \mathrm{g} \mathrm{sm}^{-3}\right)$ & 0.05 & 0.04 & 13 & AMS \\
$\mathrm{BC}\left(\mu \mathrm{g} \mathrm{sm}^{-3}\right)$ & 0.0176 & 0.074 & 399 & $\mathrm{SP} 2$ \\
\hline
\end{tabular}




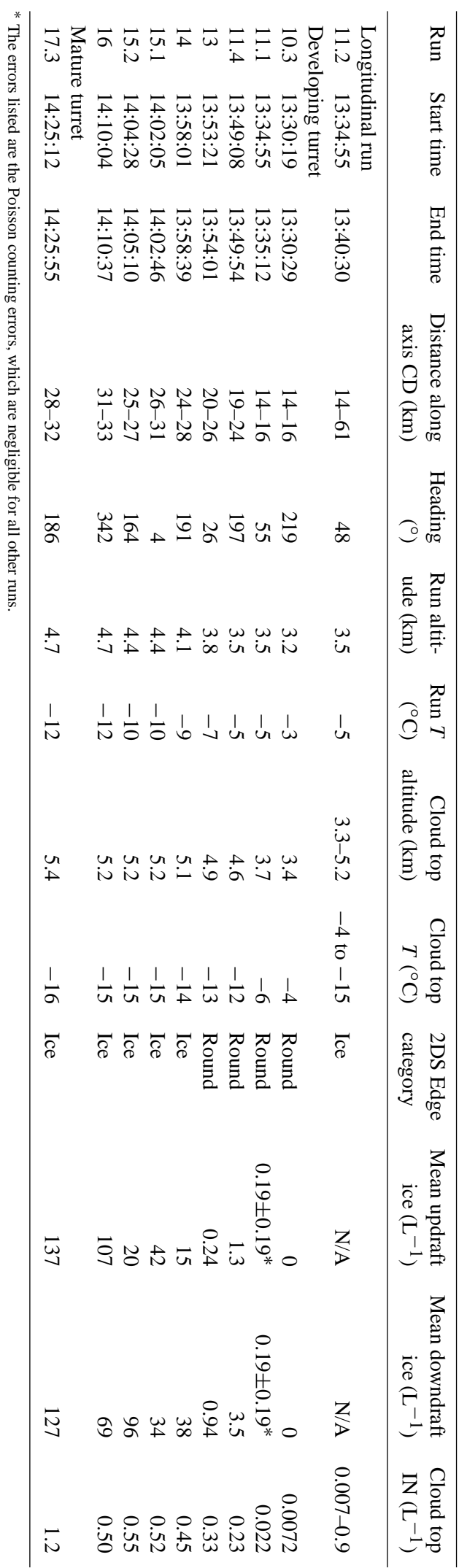

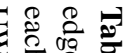
$\therefore$ 要 $\sum \tilde{\Xi} \tilde{\Omega}$ $\approx$ 효 $\approx N \cong$ 象 arated from this line, but subsequently developed to merge with a section downwind as it glaciated. Finally, we present data from a penetration through the next cloud upwind, which showed evidence of the same microphysical processes occurring.

\subsection{Characterisation of a line of closely packed cells}

Between 13:25 and 13:41 UTC, the BAe-146 flew three runs along a section of closely packed cells along line $\mathrm{CD}$, at temperatures between -5 and $-6{ }^{\circ} \mathrm{C}$. The clouds formed a quasistationary convective line with regenerating upwind convective cells. The ground-based precipitation radar observed newly formed cloud regions increasing in height and reflectivity as they matured and moved downwind. The timescale from initiation, development of precipitation, and dissipation was of the order of $1 \mathrm{~h}$, though mixing between different cloud regions meant the precise age of any one region was often difficult to determine. The clouds were semi-continuous at the flying level, but had distinguishable tops. Figure 5 shows in situ microphysical data recorded during one of these runs, as well as images recorded by the 2DS in highlighted sections. The upwind $(<35 \mathrm{~km}$ along axis $\mathrm{CD})$ section of the line sampled tended to be mostly composed of liquid drops $<50 \mu \mathrm{m}$, whereas in the section $35-60 \mathrm{~km}$ along axis CD the cloud was mostly glaciated.

The variable $R_{32}$ in Fig. 5 is defined as the ratio of the third to the second moment of the hydrometeor size distribution generated by combining all-accept data from the CDP, 2DS, and CIP100. For spherical drops, this is the same as the effective radius; when used in clouds containing nonspherical ice particles it is simply a useful indicator of the average particle size. $R_{32}$ showed a general increase between 20 and $60 \mathrm{~km}$ along axis $\mathrm{CD}$, with the largest ice around $50-55 \mathrm{~km}$ along axis $\mathrm{CD}$. There was, however, a high degree of spatial inhomogeneity; the cloud phase and the concentrations and size of ice and liquid drops varied every $0.5-3 \mathrm{~km}$. Figure $4 \mathrm{a}$ shows that point $\mathrm{C}$ is close to the origin of the line of clouds, but new updraft cells also emerged further downwind. Some are visible on Fig. 5 (e.g. at 30, 33, and $56 \mathrm{~km}$ along axis CD), but new cells also developed to the northeast of point D.

Dynamically, the upwind section of the line sampled $(<35 \mathrm{~km}$ along axis CD) was more active, with the strongest vertical motion in the liquid and mixed-phase parts. The more mature, glaciated stratiform regions were mostly quiescent. The spatial scale of the vertical motion was shorter than that of the composition, varying every $50-500 \mathrm{~m}$, though some sections were consistent for a few kilometres. Blyth et al. (2005) also reported two length scales in small cumulus in Florida, one (around $1 \mathrm{~km}$ ) associated with the width of the clouds and one $(200-500 \mathrm{~m})$ associated with the structure of the thermals. In Fig. 5, there is evidence from the vertical wind structure and concentration of cloud drops that several clouds had merged along the line. 

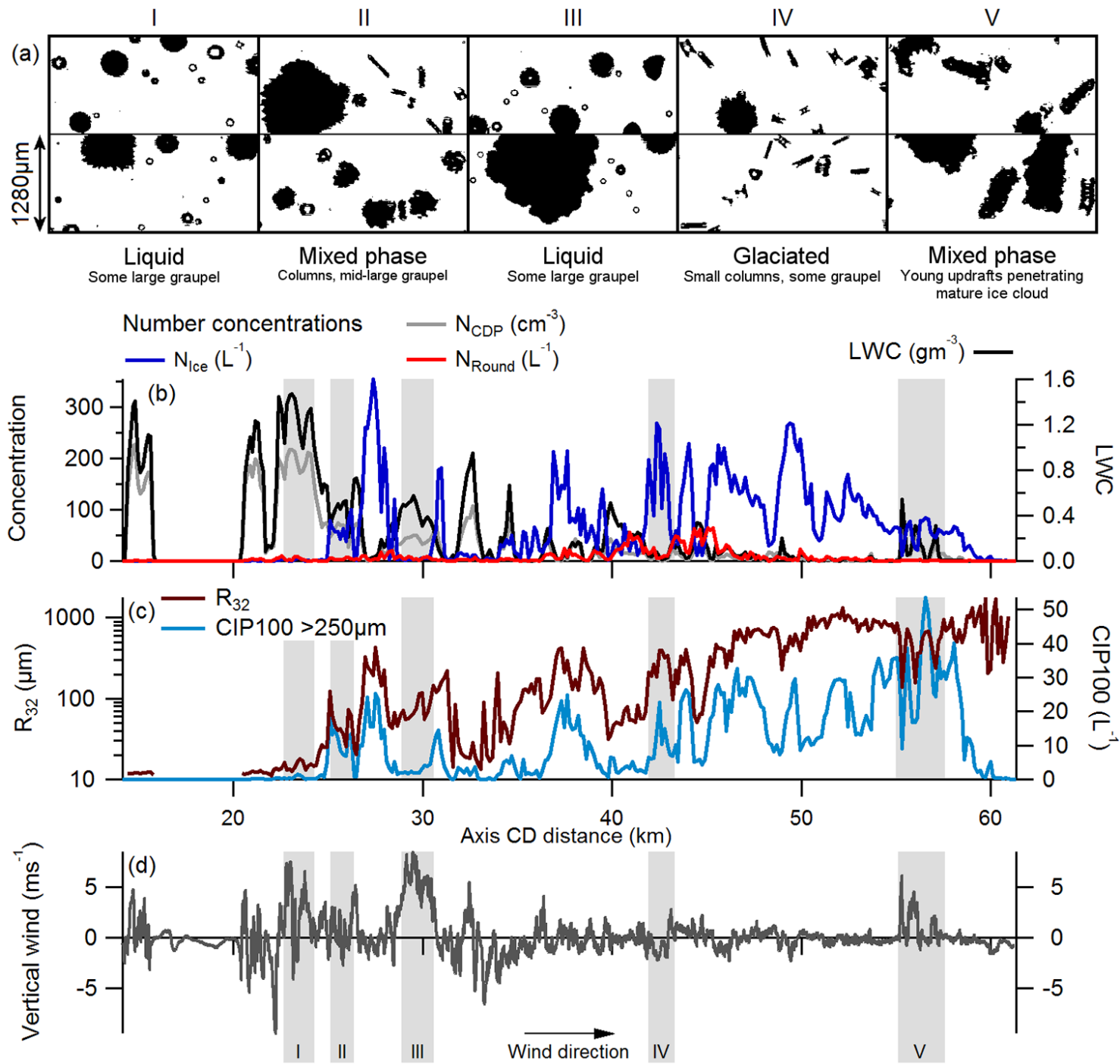

Figure 5. In situ measurements made by the BAe-146 on longitudinal run 11.2 along axis $\mathrm{CD}$. The run was made at an altitude of $3.5 \mathrm{~km}$ ( $T \sim-5^{\circ} \mathrm{C}$ ) between 13:34:55 and 13:40:30 UTC. In panel (b), the number concentrations use the left axis, and the units are defined according to the measurement probe. The 2DS categories are defined in Appendix A1. The images shown were recorded by the 2DS and show representative images from the sections marked by grey boxes and labelled with Roman numerals. Only images $>50$ pixels are shown, and they are not classified by shape.

In Fig. 5 we highlight five regions (marked by Roman numerals) to identify key processes occurring in the cloud at this level. These vary in phase, ice habit, and dynamical structure. Regions I-III were parts of the line that had emerged 30 min earlier, but was still active dynamically, with new cells emerging on the edges of pre-existing cloud regions. Regions IV and V were further downwind in a region that originated around an hour earlier, passed through a dynamically active phase, but was now quiescent and stratiform. The reader should consult Appendix A1 for details of the 2DS categories. Our constraint on cloud-top temperature is limited in this case as it was above the maximum elevation of the precipitation radar for most of the run, but it is possi- ble to provide an estimate that is likely to be accurate within a few degrees Celsius.

Region I contained clouds that were composed almost entirely of liquid drops $<50 \mu \mathrm{m}$. $N_{\mathrm{CDP}}$ was around $200 \mathrm{~cm}^{-3}$. The LWC was up to $1.47 \mathrm{~g} \mathrm{~m}^{-3}$, and the effective radius was $\sim 14 \mu \mathrm{m}$. The LWC was the highest that was measured on this run, meaning this region had undergone less of the processes that deplete liquid water (entrainment, precipitation, and ice formation) than other regions on this run. The BAe146 passed through the centre of the cell, so reduced entrainment would be expected in this region compared to the regions downwind where the aircraft flew through the cloud edges. Dynamically, this region contained two updrafts up to 
$7 \mathrm{~m} \mathrm{~s}^{-1}$ separated by a thin downdraft of $4 \mathrm{~m} \mathrm{~s}^{-1}$. The concentrations of particles measured by the 2DS that were large enough to be classified by shape $\left(N_{\mathrm{D} 90},>\sim 90 \mu \mathrm{m}\right)$ were $2-12 \mathrm{~L}^{-1}$ in total. Around half were classed as low irregularity (LI) meaning they were larger liquid drops, and the rest were rimed graupel. In contrast, almost no ice was measured in the pass through the young cell on the upwind end of Fig. 5 (around $15 \mathrm{~km}$ ). The graupel may have precipitated from cloud top, which was likely within a few degrees of $-11^{\circ} \mathrm{C}$, or been brought down in the downdraft. In liquid clouds such as this, the cloud-top height (and temperature) are likely to be an underestimate (overestimate), as the precipitation radar is unable to detect the low reflectivities at the very top of the cloud.

Region II was mixed phase, with $\sim 0.5 \mathrm{~g} \mathrm{~m}^{-3}$ of liquid water and $39-78 \mathrm{~L}^{-1}$ of ice. Dynamically, the region was a mix of updrafts and downdrafts up to around $\pm 3 \mathrm{~m} \mathrm{~s}^{-1}$ which, combined with the presence of ice, suggest a more mature cloud than in region I. The ice habits were a mix of pristine columns, hollow columns and small to large graupel.

Region III contained a cell with an updraft of $5-8 \mathrm{~m} \mathrm{~s}^{-1}$. The phase was similar to region I in that it was composed almost entirely of liquid drops, but $N_{\mathrm{CDP}}$ and the LWC were around one-third of those in region I. The BAe-146 passed through the northern edge of this cell, and did not penetrate the region of highest radar reflectivity (not shown). The LWC and cloud-drop concentration are likely to have been higher in the cell centre. $N_{\text {Round }}$ was slightly higher than in region $\mathrm{I}$, up to $9 \mathrm{~L}^{-1}$, and the graupel concentrations were around $5 \mathrm{~L}^{-1}$. The NCAS precipitation radar data suggested the cloud top was within a few degrees of $-9^{\circ} \mathrm{C}$. On the edges of region III were downdrafts of $\sim 2 \mathrm{~m} \mathrm{~s}^{-1}$ containing over $100 \mathrm{~L}^{-1}$ of columnar ice in downdrafts. These may represent more mature regions of this cloud, where ice particles had time to grow to $>90 \mu \mathrm{m}$ to be classified as ice by the 2DS.

Region IV contained mature, glaciated cloud with 90$270 \mathrm{~L}^{-1}$ of ice and very few liquid drops. The ice crystals were mostly pristine columns and hollow columns, with some graupel. The region was fairly quiescent, with a slight downdraft of up to $2 \mathrm{~m} \mathrm{~s}^{-1}$. Further downwind, regions with similar phase but larger effective radius were composed of larger columns and aggregates.

Region V showed the top of a new updraft cell (or possibly multiple cells) penetrating through a pre-existing region of ice cloud containing $60-80 \mathrm{~L}^{-1}$ of mature columns and aggregates. Regions of updraft up to $6 \mathrm{~m} \mathrm{~s}^{-1}$ were seen, containing LWC up to $0.5 \mathrm{~g} \mathrm{~m}^{-3}$, and also ice with the same habits as the ice regions, although in lower concentrations of $10-50 \mathrm{~L}^{-1}$. As in region III, the BAe-146 passed through the northern edge of these new cell(s); therefore, the LWC and cloud-drop concentrations were likely higher in the centre of the new updraft cell, where the radar reflectivity was higher. Following the aircraft penetration, these new updrafts developed into a reinvigorated dynamic cloud system.
In summary, a run along the line of cloud at $T \sim-5^{\circ} \mathrm{C}$ showed closely packed cells, each at a different level of maturity and with different cloud drop and precipitation size, phase, and dynamic structure. The upwind end of this section of the line contained mostly less-developed clouds comprised of liquid cloud drops, whereas further downwind the clouds were mostly glaciated, containing columns, aggregates and rimed graupel. The predominantly liquid clouds with tops colder than $\sim-9^{\circ} \mathrm{C}$ contained graupel in concentrations of a few per litre. New updrafts further downwind penetrating pre-existing regions of ice cloud contained mature ice, as would be expected if ice and precipitation particles were being recirculated into new updrafts. At this altitude and temperature level, the highest ice concentrations were associated with high concentrations of columnar crystals, which are the preferred growth habit close to water saturation. We infer from this that these high concentrations of columnar ice crystals must have spent most of their lifetime at or near this altitude, rather than being transported from above or below.

\subsection{Glaciation within a confined cloud region}

On the left (upwind) side of Fig. 5 is a newly developing cloud, horizontally separated from the continuous line by $\sim 5 \mathrm{~km}$. Between 13:30 and 13:50 UTC, the BAe-146 made three passes through this turret at the southwest end of longitudinal runs along the line. It then made a further five runs, at increasing altitude, aiming specifically at this cloud, over a period of $20 \mathrm{~min}$. Over a similar time period, the UWKA also made four passes over or penetrating the top of the cloud, the first and last of which are shown in Fig. 6. In total, this particular cloud region was sampled over a period of $\sim 40 \mathrm{~min}$ as it moved downwind, during which time multiple updraft thermals would be expected to develop and decay, each lasting 5-10 min (French et al., 1999). The development of, and interactions between, neighbouring and successive thermal cells will have redistributed particles and water vapour within the cloud region, but its isolation ensured it was not seeded with ice from a pre-existing cloud. Though these interactions may have acted to facilitate, enhance, or inhibit the different microphysical ice formation processes, it is not in the scope of this analysis to fully investigate such interactions.

\subsubsection{Overpass and cloud-top characterisation}

For the overpass, shown in the left side of Fig. 6, the aircraft was $\sim 1.5 \mathrm{~km}$ above cloud top, so the in situ probes did not measure any cloud particles. The value of the reflectivity was relatively low (generally below $-5 \mathrm{dBZ}$ ), meaning that precipitation-sized particles can only have been present in small concentrations. For comparison, the peak reflectivity of $-3 \mathrm{dBZ}$ is equivalent to a concentration of $0.5 \mathrm{~m}^{-3}$ of $1 \mathrm{~mm}$ raindrops, $500 \mathrm{~L}^{-1}$ of $100 \mu \mathrm{m}$ drops, or $2000 \mathrm{~cm}^{-3}$ of $25 \mu \mathrm{m}$ drops. The vertical velocity data in Fig. 6d show the 

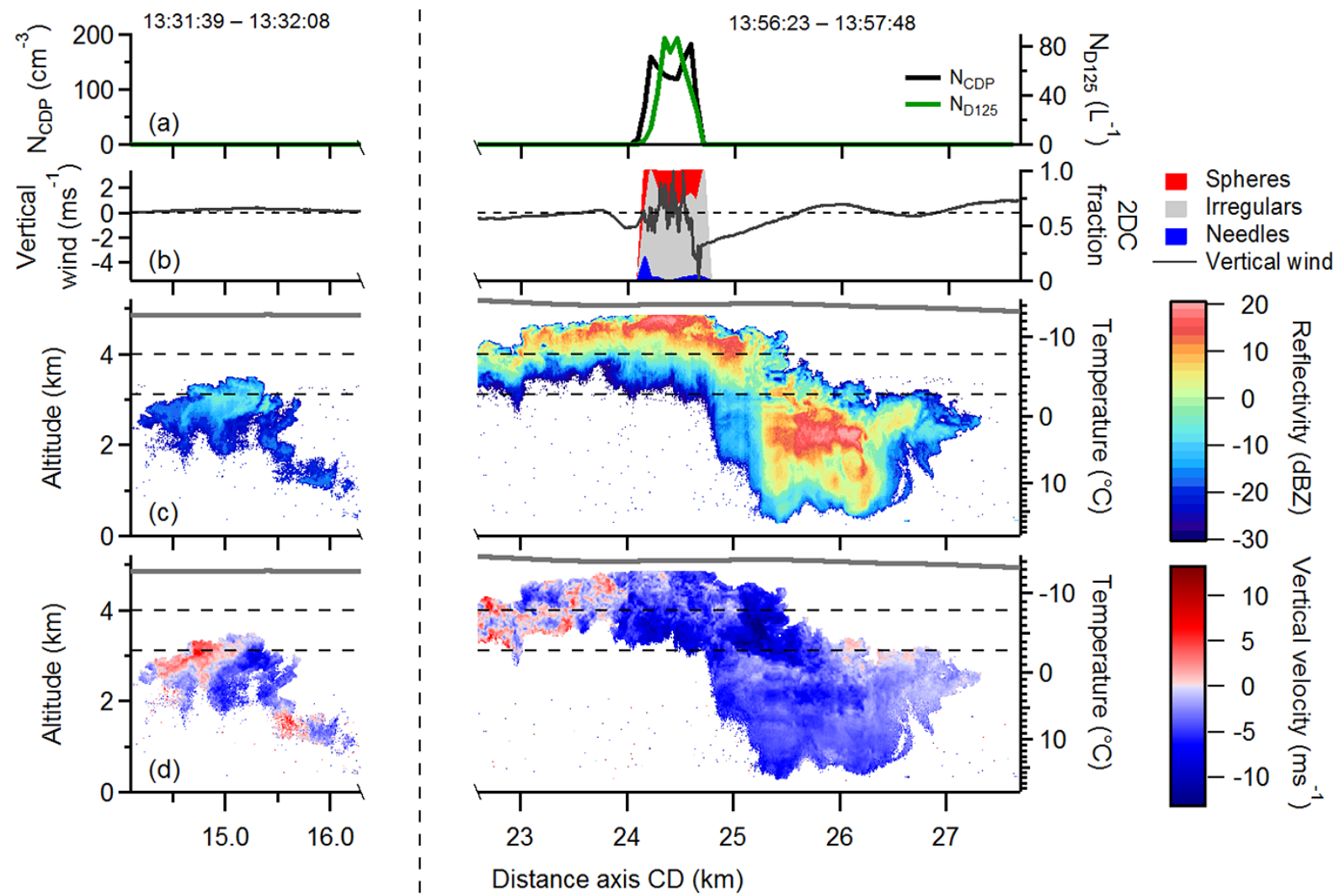

Figure 6. In situ and downward-pointing radar data measured aboard the UWKA during an overpass of a developing turret, and a penetration through the top of the same cloud 25 min later. Panel (a) shows in situ concentrations $\left(N_{\mathrm{CDP}}\right.$ and $\left.N_{\mathrm{D} 125}\right)$, which were measured by the CDP and CIP25. Panel (b) shows the habit classifications of particles measured by the CIP25, and the in situ vertical wind velocity. The horizontal dashed line on panel (b) is the zero line for the vertical wind. Panels (c) and (d) show radar reflectivity and hydrometeor vertical velocity, respectively. The horizontal dashed lines on panels (b) and (c) mark the H-M temperature zone, and the grey line shows the altitude of the UWKA during the passes.

vertical motion of the hydrometeors, which is the net sum of the motion of the air parcel and the motion of particles falling gravitationally through it. Therefore, in regions of upward vertical motion, the air is unambiguously moving upwards, whereas a net downward motion of particles may be due to downdraft and/or falling precipitation. Dynamically, the main turret was split in two, with an updraft region (up to $7 \mathrm{~m} \mathrm{~s}^{-1}$ ) on the upwind side and downdraft section (up to $9 \mathrm{~m} \mathrm{~s}^{-1}$ ) on the downwind side. Similar longitudinal runs sampled by the WCR, and cross sections along the wind direction using the NCAS precipitation radar data, showed that features in this line often had a similar diagonal structure, though not always such a clear divide between different dynamic regions. In this case, the low reflectivity suggests the cloud drops were relatively small, meaning the net downward motion is unlikely to be caused by precipitation. The vertical wind shear, with stronger winds aloft, meant the features had a diagonal divide rather than vertical.

During the run at 13:56 UTC, the UWKA penetrated cloud top at an altitude of $4860 \mathrm{~m}\left(T \sim-13^{\circ} \mathrm{C}\right)$. The value of reflectivity was higher than in the overpass that had oc- curred 25 min prior, meaning the average particle sizes had increased compared to the previous pass. Between 22.5 and $24.7 \mathrm{~km}$ along axis CD the WCR could not observe the lower sections of the cloud due to beam attenuation by the larger particles. There was still a clear region of falling particles downwind, which persisted down to ground level, and the updraft region was less continuous, which may be due to turbulent motion or large precipitation falling through a more continuous updraft region. The in situ wind measured at cloud top showed several small pockets of updrafts of a few metres per second, and a $4 \mathrm{~m} \mathrm{~s}^{-1}$ downdraft on the downwind side.

$N_{\mathrm{CDP}}$ at cloud top was $120-180 \mathrm{~cm}^{-3}$, and the concentration of particles larger than $125 \mu \mathrm{m}\left(N_{\mathrm{D} 125}\right)$ measured by the CIP25 was $\sim 80 \mathrm{~L}^{-1}$. Across the whole penetration, the habit classifications for particles $>125 \mu \mathrm{m}$ were $69 \%$ irregulars, $29 \%$ spheres, and $2 \%$ needles, meaning there was $>50 \mathrm{~L}^{-1}$ of ice at cloud top. The droplet concentrations at cloud top were lower than those in young clouds in Fig. 5, but similar to some sections of mixed-phase cloud and penetrations near the edge of liquid turrets. 

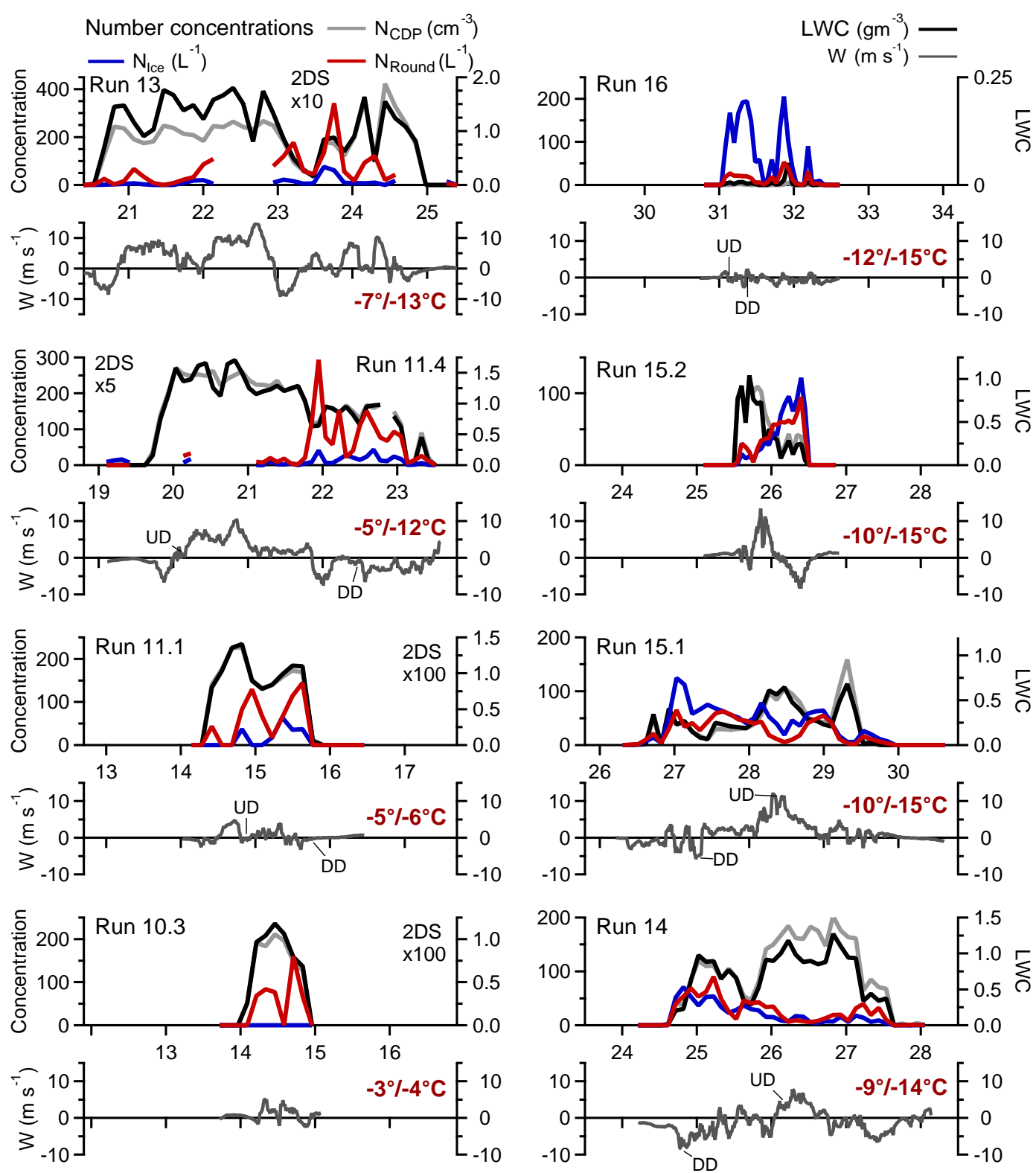

Figure 7. In situ data measured aboard the BAe-146 during a series of runs following an initially isolated turret as it moved downwind, growing in height and glaciating as it spread to join the preceding line. The $x$ axis is the same as in Figs. 5 and 6 . The colours of the traces shown are the same as in Fig. 5. For clarity, the 2DS traces ( $N_{\text {Ice }}$ and $\left.N_{\text {Round }}\right)$ in runs 10.3-13 are multiplied by factors listed in the corresponding panel. The text in red shows the run temperature and the cloud-top temperature. Further information for each run are listed in Table 2. For reference, concentrations during run 16 would have been recorded $17 \%$ lower than those during run 10.3 due to the change in temperature and pressure with altitude. The regions marked "UD" and "DD" show where the updraft and downdraft images in Figs. 8 and 9 are taken from.

\subsubsection{In situ characterisation}

The BAe-146 made a series of runs through the developing cloud, increasing in altitude with time. The cloud composition and vertical velocity from these runs are shown in Fig. 7, and the maximum ice concentrations measured in updraft and downdraft regions, as well as the run/cloud-top altitude/temperature and calculated IN concentrations, are listed in Table 2. The reported cloud-top altitudes are the maximum within the turret, based on observations made by the UWKA radar/lidar and NCAS precipitation radar during the same time period. It is clear though in Fig. 6 that, within the main turret, cloud top varied by up to $\sim 800 \mathrm{~m}$. The predicted IN concentrations are calculated using the DeMott et al. (2010) parametrisation, and are discussed further in Sect. 3.4. Figures $8-10$ show images recorded by the 2DS and CPI during 
Run 11.1 Run 11.4 Run 14 Run 15.1 Run 16

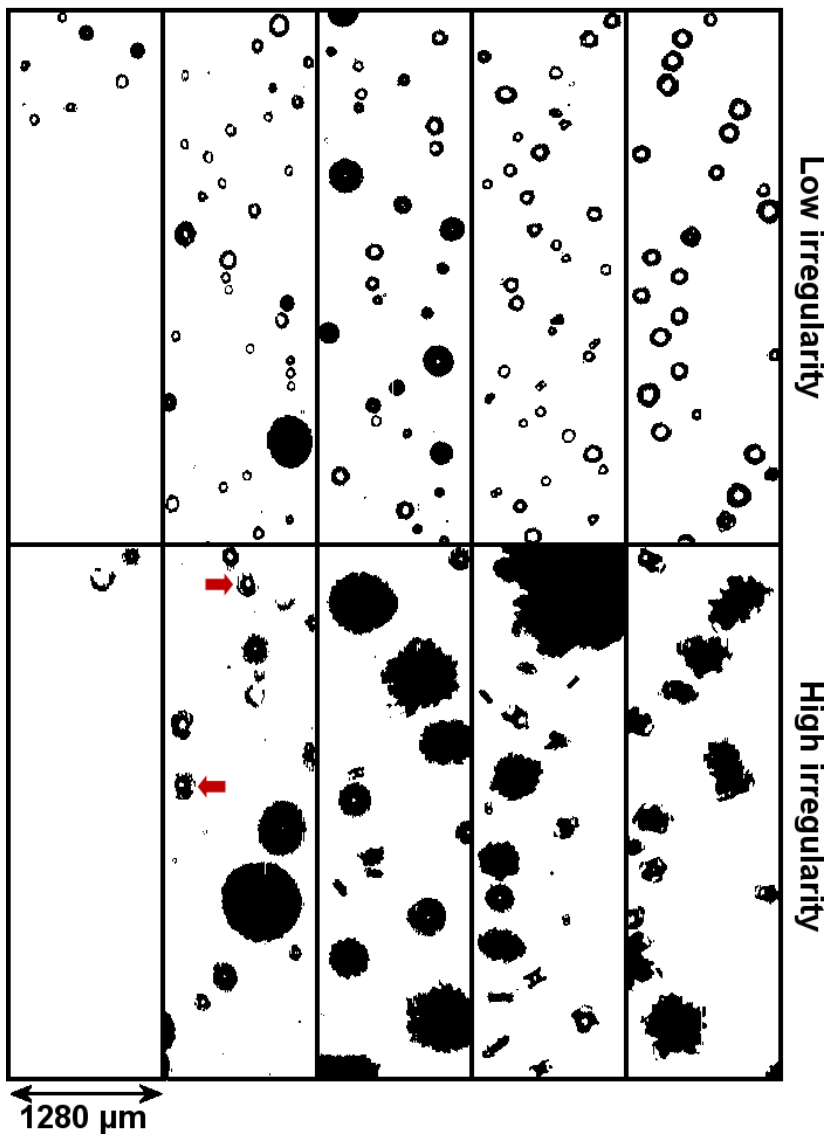

Figure 8. Images of hydrometeors measured by the 2DS during updrafts in selected runs from Fig. 7. Images with holes in the centre are out of focus. The images highlighted by red arrows are examples of frozen drops that may have also grown by vapour diffusion, as discussed in the text.

selected runs, and Fig. 11 shows the ground-based radar reflectivity to place each run into context, showing the horizontal cloud structure and the part of the cloud the aircraft passed through. For safety reasons, the BAe-146 avoided regions of highest reflectivity, meaning some of the passes were not through the centre of the turret. Consequently, in some of the cloud penetrations, particularly the later penetrations where the cloud was more developed and reflectivity was higher, the LWC and updraft strength may be biased low compared to the updraft cores.

As a general trend, in the earlier, lower altitude runs, the cloud was composed almost entirely of liquid cloud drops, and the peak LWC increased with altitude. This trend proceeded until significant precipitation was observed, at which point the LWC began to decrease, likely by scavenging and entrainment. At increasing altitude/time, the cloud shifted to mixed phase and finally was nearly glaciated in the final run. Some variations in maturity of cloud regions, and concentrations within those regions, are to be expected due to pene-
Run 11.1 Run 11.4 Run 14 Run 15.1 Run 16

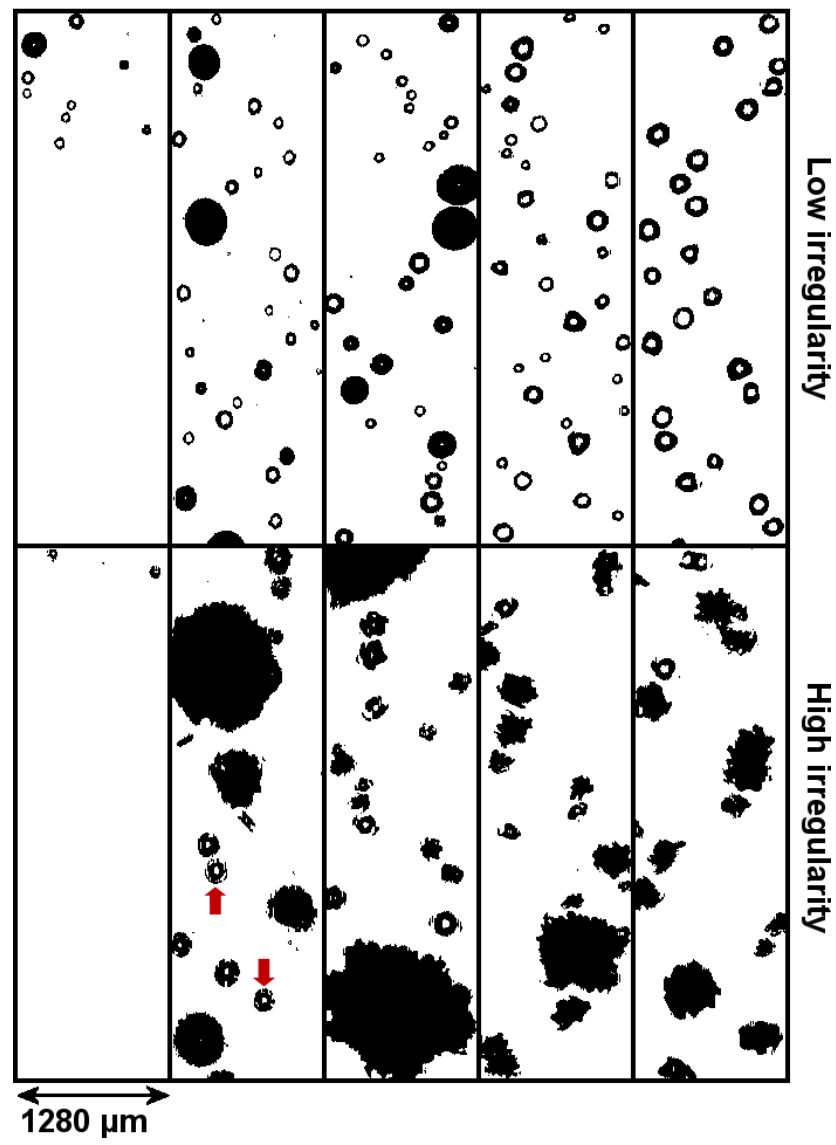

Figure 9. As in Fig. 8, but for downdrafts.

trations through different parts of the cloud, but the general progression from young liquid cloud to mature ice cloud was still clear, as was the timescale over which this transition took place.

The first two runs in the turret (runs 10.3 and 11.1) took place at temperatures of -3 and $-5^{\circ} \mathrm{C}$. The aircraft flew approximately parallel to the wind direction, and passed close to the cell centre in both penetrations. There were two main updrafts up to $4-5 \mathrm{~m} \mathrm{~s}^{-1}$, with downdrafts up to $2 \mathrm{~m} \mathrm{~s}^{-1}$ at the edges and in the centre. In run 11.1, the downwind updraft region was more turbulent, with vertical velocity varying on the scale of tens of metres, where the upwind updraft was $300 \mathrm{~m}$ wide. On both runs, the cloud was composed of up to $\sim 200 \mathrm{~cm}^{-3}$ of cloud drops measured by the CDP, with LWC of $0.8-1.4 \mathrm{~g} \mathrm{~m}^{-3} . N_{\mathrm{D} 90}$ measured by the 2DS was $<2 \mathrm{~L}^{-1}$, and the measured particles were almost all round. Some of the 2DS images were classed as high irregularity (HI), but it is difficult to tell if they were ice or just poorly imaged drops. The high concentration of cloud drops meant the 2DS dead time fraction was high, and only a few D90 images were recorded, so the measured concentrations have a high counting error. 


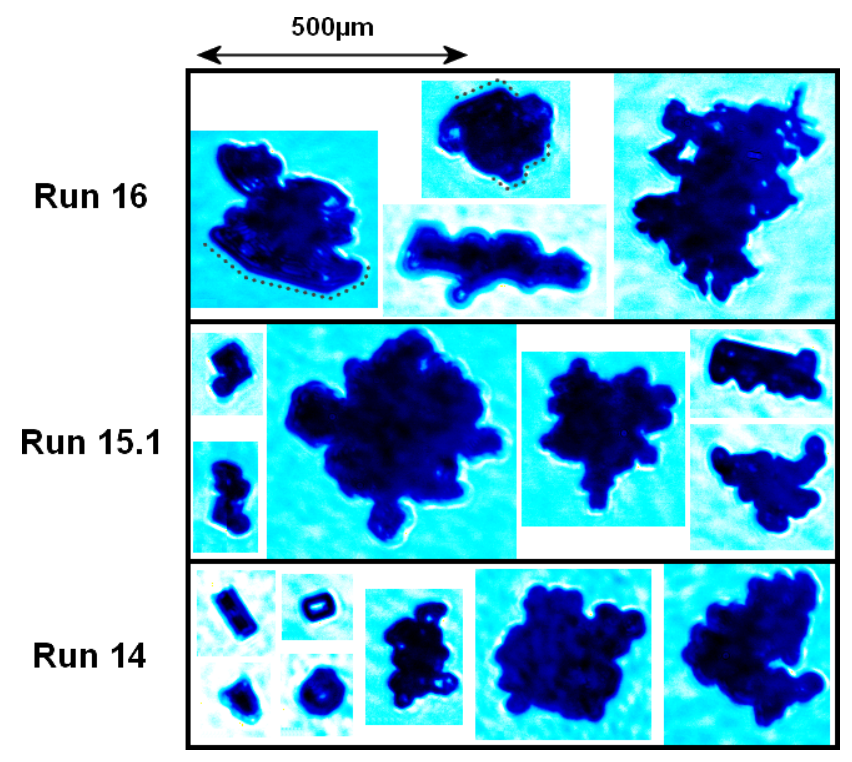

Figure 10. Images of hydrometeors measured by the CPI during selected runs from Fig. 7. Only a few images were recorded on each run, so they are not classified by vertical velocity. The dashed lines are to aid the reader's eye to the plate-like features, which may be difficult to see otherwise.

14 min later the BAe-146 made another run (run 11.4) at the same altitude as run 11.1, though in this time the cloud top had risen $\sim 900 \mathrm{~m}$, and decreased in temperature from -6 to $-12{ }^{\circ} \mathrm{C}$. The aircraft passed through two distinct regions: one containing updrafts $2-10 \mathrm{~m} \mathrm{~s}^{-1}$ and the other downdrafts of $0.5-7 \mathrm{~m} \mathrm{~s}^{-1}$. The upwind side was a newer, younger updraft region developing on the side of the previous cell. The updraft side had higher LWC of $1.1-1.7 \mathrm{~g} \mathrm{~m}^{-3}$, compared to $0.6-1.0 \mathrm{~g} \mathrm{~m}^{-3}$ in the downdraft. $N_{\mathrm{CDP}}$ followed a similar trend, with $220-280 \mathrm{~cm}^{-3}$ in the updraft and 120 $170 \mathrm{~cm}^{-3}$ in the downdraft. Although some 2DS data are missing in the updraft section due to instrument saturation, it is still clear from the remaining data that $N_{\mathrm{D} 90}$ was significantly higher in the downdraft section, with $N_{\text {Round }}$ of 5-60 L $\mathrm{L}^{-1}$ and $N_{\text {Ice }}$ of $1-9 \mathrm{~L}^{-1}$, compared to $N_{\text {Round }}$ of $0.4-$ $7 \mathrm{~L}^{-1}$ and $N_{\text {Ice }}$ of $0.4-3 \mathrm{~L}^{-1}$ in the updraft. In the downdraft in run 11.4, the ice particles were fairly circular in shape, suggesting they had originated as frozen drops. However, there is also some evidence of riming, and the smaller particles had a banding near the edge, which may suggest a surface structure similar to the ridges often found on thin plates, though it is possible this banding is an optical/instrumental artefact. A few images of columns were also recorded. In the updraft, the images classed as HI were also fairly round, meaning they were either recently frozen drops or simply poorly imaged drops. The larger frozen drops were less rimed than in the downdraft, but some smaller particles also showed the banding present in the downdraft.

Run 13 took place 4 min after run 11.4, and $300 \mathrm{~m}$ higher in altitude, but showed similar structure of an upwind side dominated by cloud drops in a strong updraft, and a downwind side with greater concentrations of particles large enough to be detected by the 2DS. The precipitation radar showed two distinct cells, and the aircraft passed close to the centre of both. The 2DS images in run 13 were similar to those from the previous run, with a mix of drops, recently frozen drops, and rimed round graupel. Compared to run 11.4, the downwind side was more turbulent, and was predominantly updraft, whereas a similar region in run 11.4 was predominantly downdraft. The LWC in the main updraft region reached $1.8 \mathrm{~g} \mathrm{~m}^{-3}$, the highest that was detected in this developing cloud. $N_{\mathrm{CDP}}$ was also high here, at 170 $270 \mathrm{~cm}^{-3}$, but the highest droplet concentration was measured in the downwind side, where a small section of cloud contained $N_{\mathrm{CDP}}$ of $420 \mathrm{~cm}^{-3}$ in a $10 \mathrm{~m} \mathrm{~s}^{-1}$ updraft.

The next four runs were made at more oblique angles to the wind direction. By run 14, the precipitation radar showed additional updraft cells/thermals had emerged on the downwind side. This cloud penetration showed several distinct sections; a central updraft of $1-8 \mathrm{~m} \mathrm{~s}^{-1}$, close to the peak radar reflectivity, surrounded by dynamically mixed regions, and downdrafts on both the upwind and downwind edges that were of similar strength to the updraft region. The peak LWC and $N_{\mathrm{CDP}}$ in the updraft region were $1.2 \mathrm{~g} \mathrm{~m}^{-3}$ and $\sim 180 \mathrm{~cm}^{-3}$, respectively, which were around one-third lower than in the previous run. $N_{\text {Ice }}$ and $N_{\text {Round }}$ in the updraft were higher than in the previous two runs, with $N_{\text {Ice }}$ ranging $4-15 \mathrm{~L}^{-1}$, and $N_{\text {Round }}$ ranging $7-30 \mathrm{~L}^{-1}$. The images in Fig. 8 show ice in the updraft was a mixture of small columns, frozen drops, and rimed ice. The frozen drops had some riming but were still recognisable as frozen drops, so are likely to have frozen fairly recently.

Compared to the updraft region, the 2DS measured enhanced concentrations in both downdrafts, with $N_{\text {Round }}$ up to $90 \mathrm{~L}^{-1}$ and $N_{\text {Ice }}$ up to $71 \mathrm{~L}^{-1}$. These are far in excess of the concentrations seen lower down in the cloud. Although newly developing cells on the downwind side had begun to fill the gap between the cloud region in question and cloud downwind, the highest ice concentrations in this run were sampled on the upwind side, meaning they cannot have been mixed in from a cloud further downwind. The images in the downdraft show large graupel and small irregular ice of indeterminate habit. The CPI images from run 14 (Fig. 10) show pristine and rimed columns and heavily rimed particles.

The BAe-146 passed through the same part of the cloud in the next run, run 15.1, and measured a similar dynamical structure. Compared to the previous run, $N_{\text {Ice }}$ and $N_{\text {Round }}$ were enhanced in the central updraft region, ranging 19-78 and $5-40 \mathrm{~L}^{-1}$, respectively. $N_{\mathrm{D} 90}$ decreased towards the centre of the updraft region, which suggests the larger particles had been mixed in and recirculated from more mature regions. The images in Figs. 8 and 9 show these were a mix of small columns/hollow columns and small to large graupel. The LWC in the cloud drops was significantly lower than previous runs, peaking at $0.7 \mathrm{~g} \mathrm{~m}^{-3}$, suggesting one, or some 

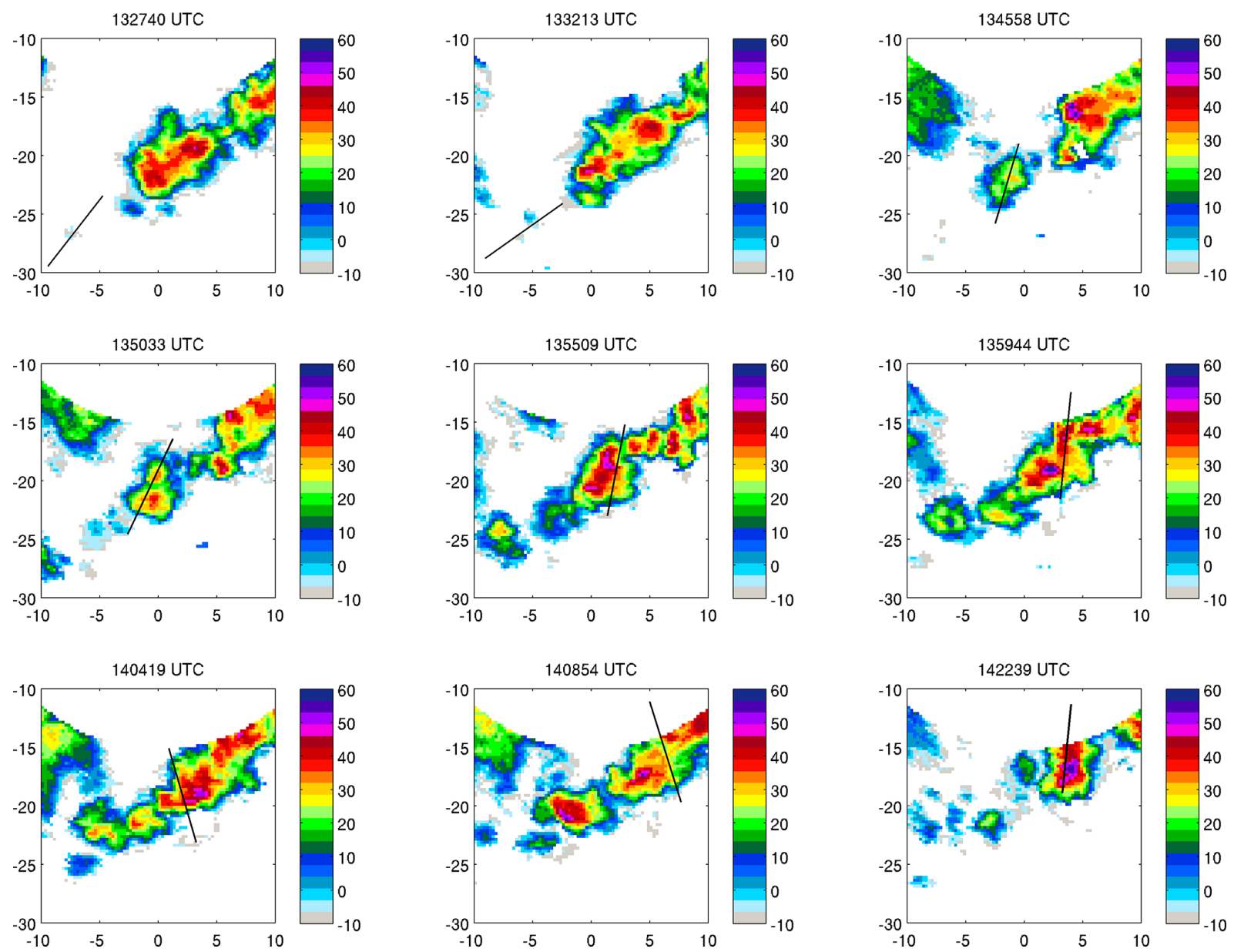

Figure 11. Radar reflectivity at $3.5 \mathrm{~km}$ altitude, measured by the NCAS precipitation radar during each of the runs shown in Fig. 7. The $x$ and $y$ axes are a Cartesian grid, showing kilometres east and west of the radar site, and the colour scale is in units of dBZ; 1 min of flight track is shown for each run.

combination of all of the following: some of the small liquid drops had coalesced to form larger drops, some liquid water had changed to ice, and/or entrainment had diluted the cloud with dry air. Ice images in the downdraft were rimed small irregular ice, rimed columns, and graupel, and two particles imaged by the CPI had plate-like features, suggesting they had grown in part by vapour deposition at temperatures $<-10^{\circ} \mathrm{C}$.

Run 15.2 was a transect across a more upwind section than run 15.1, but showed similar ice habits. There was a clear divide between the younger updraft region dominated by cloud drops and the downdraft composed mainly of larger drops and ice.

Run 16 was the final run through this developing cloud region and, by this point, the gaps between it and the continuous line of cloud downwind had been filled. The section of cloud passed through on this run was largely quiescent. Although some small updrafts and downdrafts up to a few metres per second were present, the ice habits were very similar in these sections. The CDP measured almost zero, meaning all cloud drops had been lost by riming onto ice and/or evaporation. Some larger drops were measured on the 2DS, but in smaller concentrations than the previous few runs. The 2DS measured ice concentrations up to $205 \mathrm{~L}^{-1}$, and these were generally heavily rimed, with elongated or round shapes suggesting they originated as columns or frozen drops.

\subsubsection{Ice in the next cloud upwind}

After the runs shown in Figs. 7-11, the BAe-146 made three runs near the top of the next cloud to the southwest along line CD (i.e. upwind), which took place as the cloud moved between 23 and $32 \mathrm{~km}$ along line $\mathrm{CD}$. These runs were made at the same altitude as run 16, and were on an axis of approximately $5 / 185^{\circ}$, along which the cloud was $\sim 5 \mathrm{~km}$ wide. Data and images from the third of these runs, run 17.3, are shown in Fig. 12. There were three distinct regions in which the microphysical data were consistently different to each other, which are labelled I-III in Fig. 12. 

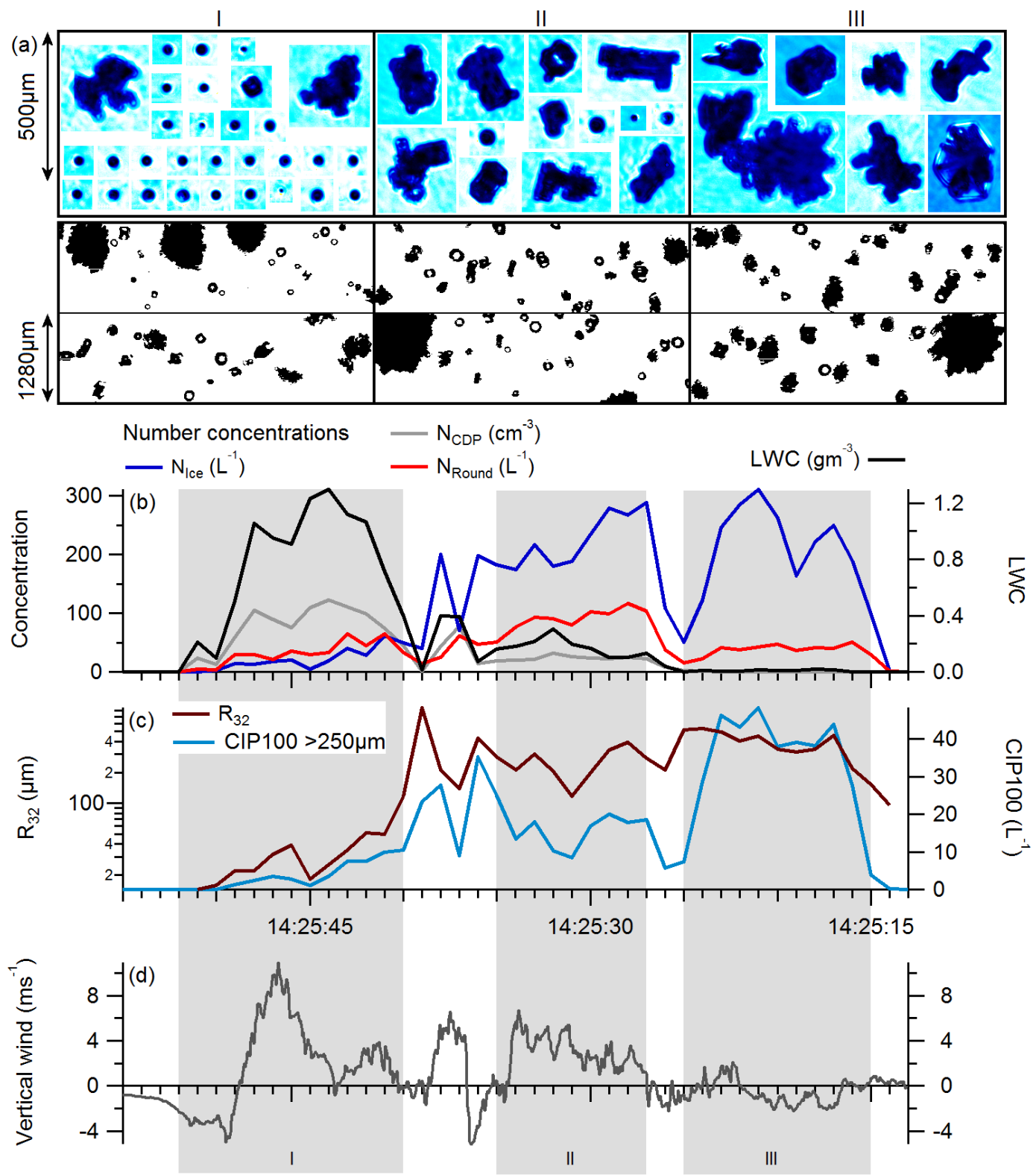

Figure 12. In situ measurements and images recorded by the BAe-146 probes during run 17.3. The time axis runs backwards for clarity in the discussion. The images shown were recorded by the 2DS and CPI probes and are representative images of particles in the sections marked by grey boxes and labelled with Roman numerals. Only images $>50$ pixels are shown from the 2DS, and they are not classified by shape.

Region I contained strong updrafts of up to $10 \mathrm{~m} \mathrm{~s}^{-1}$, and the cloud in this region was mostly comprised of liquid drops $<50 \mu \mathrm{m}$, with $N_{\mathrm{CDP}}$ up to $120 \mathrm{~cm}^{-3}$. Drizzle-sized drops (i.e. those classed as round by the 2DS) were present at concentrations of $30-65 \mathrm{~L}^{-1}$, and ice was present in concentrations of 5-60 $\mathrm{L}^{-1}$, most of which were heavily rimed graupel, with a few hollow columns. The concentrations measured by the CDP, 2DS, and CIP100 all decreased towards the downdraft section at the edge of the cloud, as did the effective radius. This reduction is likely to be due to entrain- ment of dry air into the cloud, as well as adiabatic evaporation in the downdraft.

Region II also had updrafts of up to $6 \mathrm{~m} \mathrm{~s}^{-1}$ but was mixed phase, with $N_{\text {Ice }}>170 \mathrm{~L}^{-1}$. These were mostly columns or hollow columns, meaning they had originated at temperatures between -3 and $-10^{\circ} \mathrm{C}$, where columns are the dominant mode of depositional growth. The CPI images show evidence of aggregation and some riming, but the columnar structure is still clearly visible. Compared to those in region I the ice particles were larger, and the LWC of the cloud drops was much lower. This was likely due to riming and conver- 
sion to ice via the Bergeron-Findeisen process, which may have occurred lower down in the cloud.

Region III represents a mature stage of the cloud, similar to that observed in run 16, and contained the largest particles in this cloud. This region was mostly in a weak downdraft of up to $2 \mathrm{~m} \mathrm{~s}^{-1}$, and the cloud drops had been entirely depleted, leaving only ice and some larger round drops left. The ice was heavily rimed, and displayed a mixture of plate-like and columnar features.

\subsection{Summary of ice measurements}

\subsubsection{The formation of first ice}

Section 3.3 described the glaciation of a cloud as it developed from an isolated young cloud into a mature region of the semi-continuous line. Several possible ice-forming processes may take place in a developing cloud. Primary ice may form as drops freeze by immersion nucleation, or by contact nucleation with interstitial IN. Primary nucleation is expected to form ice in concentrations within an order of magnitude of the IN concentrations calculated using the DeMott et al. (2010) parametrisation. Clouds forming under or adjacent to existing mixed-phase or ice clouds may be seeded with existing ice, which would accelerate their glaciation. Figure 5 shows some evidence for ice seeding occurring in clouds further downwind, but Fig. 11 shows that the cloud region that was the focus of this analysis was initially isolated from neighbouring clouds by several kilometres, and no aerosol layers or regions containing outflow from previous clouds were detected in the immediate vicinity.

Figure 13 provides a comparison of the mean ice concentrations in updraft and downdraft regions in the cloud and the predicted IN concentration calculated using the DeMott et al. (2010) parametrisation, which is based on the concentration of aerosols in the boundary layer exceeding a threshold diameter of $0.5 \mu \mathrm{m}$. The aerosol concentration used in these calculations was taken from Table 1. The data from Fig. 13 are also summarised in Table 2. The DeMott et al. (2010) calculations have an uncertainty of around a factor of 10, as they do not consider aerosol composition. Cloud-top temperature was used in the calculation to provide an estimate of the upper limit of IN concentrations, as primary ice cannot form at temperatures lower than the lowest temperatures in the cloud. Ice forming at cloud top may be transported to other regions in the cloud by precipitation and/or thermal recirculation, but would take time to descend to the measurement level.

No ice particles were measured during the run with cloud top at $-4^{\circ} \mathrm{C}$, and only a few were recorded on run 11.1 , when cloud-top temperature was $-6^{\circ} \mathrm{C}$. The counting errors are large due to the poor sampling statistics, and the absolute concentrations may be biased high due to misclassified liquid particles. The mean ice concentrations were a factor of 5-15 higher than the calculated IN concentrations, which is at the upper end of what might be expected from primary ice nu-

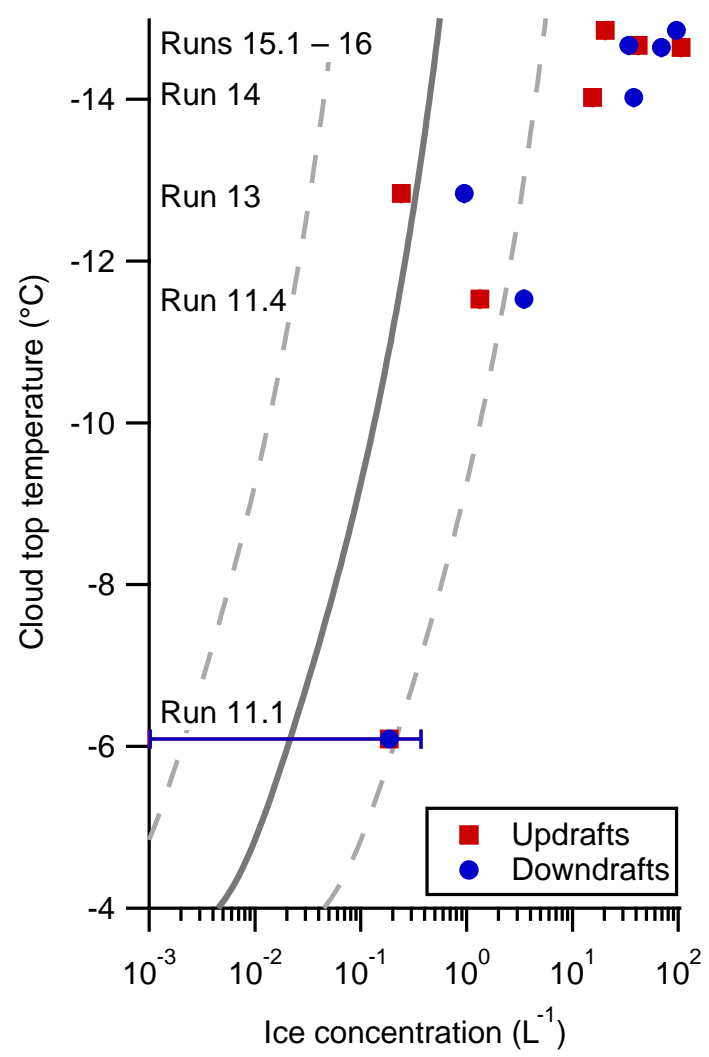

Figure 13. Mean ice concentrations measured during the runs in Figs. 7-11. The displayed errors are Poisson counting errors, which were negligible for all runs other than run 11.1. The solid grey line is the IN concentration calculated using the DeMott et al. (2010) parametrisation, and the dashed grey lines are $10 \times$ and $0.1 \times$ the DeMott et al. (2010) values.

cleation, but it is difficult to make a quantitative comparison due to the large measurement uncertainty.

The next run was made at the same measurement altitude, but around 14.5 min later. In this time, the cloud-top temperature had reached $-12{ }^{\circ} \mathrm{C}$. The ice concentrations measured at $-5^{\circ} \mathrm{C}$ had increased by around an order of magnitude, but so had the calculated IN concentrations at cloud top. The measured ice concentrations were statistically significant, and 0.7-3 times the calculated IN concentrations. Again though, poorly imaged drops may mean the ice concentrations in this run are overestimated.

The larger ice concentrations in the downdraft may suggest primary ice nucleation occurring at lower temperatures nearer cloud top. If the first ice formed predominantly from freezing small cloud drops or interstitial IN, rather than freezing drizzle, these particles would then have to grow by vapour deposition to sizes $\sim 90 \mu \mathrm{m}$ in order to be classed as ice by the 2DS. We would therefore expect to observe a larger fraction of the first ice as columns or plates, depending on the temperature at which the growth occurred. In fact, almost all the first ice images observed were frozen drizzle- 
sized drops, with variable amounts of riming. It is difficult to be definitively clear, but the evidence appears more consistent with the majority of the first ice forming as freezing drizzle.

The in situ observations during run 13 were similar to those in run 11.4, but with lower ice concentrations in the downdraft, and no columns were observed. The precipitation radar reflectivity in Fig. 11 shows two maxima at $3.5 \mathrm{~km}$ altitude, suggesting a second thermal was emerging, but at this stage any ice multiplication in updraft regions cannot have progressed to a stage where high ice concentrations had reached the downdrafts.

The ice concentrations measured in the first few runs were mostly near the upper end of what might be expected from primary nucleation, so it is possible that the ice concentrations in the early stages were enhanced by some secondary ice mechanism. The measurements are, however, not consistent with any prolific secondary ice production in these early stages.

\subsubsection{The transition to secondary ice}

As cloud top reached $-14{ }^{\circ} \mathrm{C}$, columns and rimed graupel were observed in updraft regions at $-9^{\circ} \mathrm{C}$ by the BAe-146, as well as at cloud top by the UWKA. The images from the updraft in run 14 look similar to those in the downdraft in run 11.4, meaning the particles may have been recirculated from a previous downdraft. By this stage, new updraft cells had emerged on the downwind side, which brought a new supply of liquid water to mix with downdraft and quiescent regions, and provides a mechanism to redistribute particles throughout the cloud.

Run 14 was the first run where the measured ice concentrations showed a clear enhancement compared to the calculated IN values. Values of $N_{\text {Ice }}$ measured in earlier runs were roughly within a factor of 10 of the calculated IN values, but in run 14 and subsequent runs they were $>30$ times the calculated IN concentrations, and this enhancement increased with time. These results are consistent with one or more secondary ice processes being active during these runs. We note that the highest ice concentrations measured during run 14 were measured closer to the upwind side (though the run was at a tangent to the wind axis), meaning ice seeding from preexisting mature cells downwind cannot have been the source of the increased ice concentrations.

In the later runs at higher altitude, the cloud top reached its lowest temperature of $-15^{\circ} \mathrm{C}$. The process of recirculation continued, as columns, rimed graupel, and frozen drops were found in the updraft in run 15.1.

In the mature stages, the cloud drops had been depleted through entrainment and conversion to ice, and the largest drops were fewer in number in run 16 than mature regions in the preceding few runs. Smaller droplets would have been lost by riming and all sizes of drop would shrink due to entrainment-induced evaporation. In the mature regions sam- pled lower down in the cloud on run 11.2, very few large drops were measured. These regions were generally fully glaciated, and contained only mature columns, aggregates, and graupel, though the largest graupel had precipitated out.

Run 17.3 showed the same processes were occurring in the next cloud upwind. The images in Fig. 12 are the clearest, showing the mixed-habit, rimed ice particles. Region I in Fig. 12 appeared to be a relatively young updraft composed mostly of cloud drops, with some large drops and ice. The concentrations of large drops and ice increased closer to the adjacent parts of the cloud containing more ice, as did the effective radius and concentration of large particles measured by the CIP100. Also, the ice particles that were measured in this region were rimed graupel and columns, rather than frozen drops that were present in earlier young updrafts. The concentration gradient and ice habits suggest that the ice particles in this updraft were recirculated, and that young cells emerging next to more mature ones are seeded with ice to hasten their development.

\section{Discussion}

\subsection{Comparison to August 2004 case}

The clouds in the 2004 Boscastle floods, and in the case presented in this manuscript, both formed along convergence lines over the southwest peninsula of the UK. In both cases, the convergence lines were aligned with the peninsula in predominantly southwesterly winds (Golding et al., 2005). In the August 2004 case, a single line of cloud remained quasistationary near the north coast of the southwest peninsula for a period of $4 \mathrm{~h}$. In our case, there were two lines of convective clouds, and they were both located further inland over the peninsula. The clouds were not as deep as those present in August 2004, probably due to the dry air in the mid- to upper-troposphere and weak inversion at $\sim 5 \mathrm{~km}$ that capped cloud tops. The maximum radar-estimated rainfall intensity for the clouds studied in this paper was $\sim 50 \mathrm{~mm} \mathrm{hr}^{-1}$, which is comparable to the maximum rainfall rate seen throughout much of the afternoon in August 2004, though less than the peak. The winds were stronger in this case, meaning the local duration of maximum precipitation from any individual cell was reduced by comparison to the August 2004 case. The lines in this study only persisted for around $2 \mathrm{~h}$, and no significant flooding was reported.

\subsection{Horizontal development}

During similar meteorological conditions, consecutive cumulus cells can often tend to initiate from similar locations (Bennett et al., 2006). The cloud sampled by the BAe-146 in Figs. 7-11 was initially isolated, but grew horizontally to join the semi-continuous section of cloud downwind. Figures 4 and 5 show that the cloud tended to form semi-continuous lines of closely packed cells along the wind direction. The 
last few runs in Fig. 11 also show a subsequent cloud further upwind, which was initiated from a similar location, undergoing similar behaviour, and this is the cloud sampled in Fig. 12.

During runs 10.3-11.4 the cloud sampled had a reasonably similar dynamical structure. On the upwind side, the strongest updraft contained many liquid cloud drops and few large drops or ice. The strongest downdrafts tended to be located on the downwind side, though this region was also turbulent, and contained larger drops/ice meaning it was more mature than the updraft. The vertical velocity data in Fig. 6d also show a diagonal structure; the boundary between the updraft and downdraft sections was further downwind at higher altitudes. Features exhibited similar diagonal structure in other longitudinal runs sampled by the WCR and precipitation radar, though the example shown in Fig. 6 is the clearest example of segregated updraft and downdraft regions.

This structure is a result of the unidirectional vertical wind shear in the region where the cloud developed, shown in Fig. 2. Between the altitudes of the lowest and highest runs shown in Fig. 7, the average out-of-cloud vertical wind gradient was $\sim 3 \mathrm{~m} \mathrm{~s}^{-1} \mathrm{~km}^{-1}$. This would cause a relative motion in the upwind direction (i.e. towards point C) at lower altitudes, and in the downwind direction (towards point D) at higher levels. This dynamic set-up elongates the cloud and its precipitation footprint horizontally, and aids recirculation by encouraging individual cells into this overturning structure.

Figure 11 shows the emergence of new updraft cells along the wind axis, incorporating the initially isolated cloud region into a continuous line. Similar behaviour was observed by Golding (2005) in the August 2004 case. The wind shear extends individual cells horizontally, and facilitates recirculation by mixing in adjacent thermals.

\subsection{Ice development}

\subsubsection{Generation of columns and mixed-habit ice crystals}

The observations described in Sect. 3 demonstrated several key features, which provide insight into the ice formation processes occurring in the clouds. Ice concentrations of up to several hundred per litre were observed in multiple cloud regions; first, in developing and mature cloud at $T \sim-5^{\circ} \mathrm{C}$, and then at increasing altitude (decreasing temperature) in a single developing cloud region as it matured. At $T \sim-5^{\circ} \mathrm{C}$ the ice were mostly a mixture of frozen drops and graupel in developing clouds, and columns in more mature regions. At $T \sim-10$ to $-12^{\circ} \mathrm{C}$, the ice were a mixture of frozen drops, graupel and mixed-habit ice showing columnar and plate-like features.

The habit of vapour-grown ice crystals is determined by the temperature at which they undergo growth. Ice crystals growing in the range $-3>T>-10^{\circ} \mathrm{C}$ develop columnar features, whereas crystals growing at temperatures $T<$ $-10^{\circ} \mathrm{C}$ develop plate-like features. This provides us with some information on the history of such ice crystals. The pristine columns and aggregates of columns measured in quiescent regions at $T \sim-5^{\circ} \mathrm{C}$ during run 11.2 must have formed and spent their entire lifetime at temperatures $-3>$ $T>-10^{\circ} \mathrm{C}$. Alternatively, the near-pristine columns measured at temperatures $T=-10^{\circ} \mathrm{C}$ in updrafts on run 15.1 and $T=-12{ }^{\circ} \mathrm{C}$ in updrafts on run 17.3 must have grown (and almost certainly formed) at temperatures $-3>T>$ $-10^{\circ} \mathrm{C}$ before being rapidly transported upwards. The mixed-habit columnar/plate-like ice crystals detected in quiescent regions at $T=-12{ }^{\circ} \mathrm{C}$ on runs 16 and 17.3 must have had a similar history before undergoing further growth at $T=-12^{\circ} \mathrm{C}$ to develop plate-like features, while also undergoing riming.

We may gain further evidence that the columns detected at $T \sim-12^{\circ} \mathrm{C}$ were generated by the same mechanism as those detected at $T \sim-5^{\circ} \mathrm{C}$ during run 11.2. Using the method of Harris-Hobbs and Cooper (1987), as described in Appendix A2, the calculated rate of ice production in region IV on run 11.2 (a mature region containing columns), was $0.14 \mathrm{~L}^{-1} \mathrm{~s}^{-1}$. Using the same method in region II on run 17.3 , a mixed-phase updraft region at $T=-12^{\circ} \mathrm{C}$ containing predominantly columns, gives a calculated ice production rate of $0.11 \mathrm{~L}^{-1} \mathrm{~s}^{-1}$. The consistency of these numbers provides further evidence that both sets of columns were produced by the same mechanism.

To summarise, our results suggest that one or more secondary ice processes were active at temperatures $-3>T>$ $-10^{\circ} \mathrm{C}$ and generated ice columns in concentrations of up to several hundred per litre. Some of these columns remained at similar temperatures, while others were lifted to higher levels in updrafts.

\subsubsection{Generation of frozen drops}

Although columns were the dominant ice habit in many of the mature stratiform-stage clouds measured, a large fraction of the ice particles detected were frozen drops, particularly in the mixed-phase developing stages. It is more difficult to determine the temperature at which such particles froze as they generally do not exhibit clear features of growth by vapour deposition. The time since these particles froze may be qualitatively estimated (i.e. recently frozen or not) by the degree of riming around the edges. Frozen drops with minimal riming must have frozen at or near the temperature at which they were measured, whereas more heavily rimed graupel is more likely to have frozen at lower temperatures when found in downdrafts, or higher temperatures when found in updrafts. The presence of frozen drops does not inherently reveal the origins of the ice; something must cause a drop to freeze, whether this is immersion or contact freezing with primary IN, or freezing when coming into contact with a preexisting ice crystal. The concentrations of frozen drops were well in excess of the expected IN concentrations; therefore, 
it is likely that one or more secondary ice processes were involved in freezing the drops.

Figures 7 and 13 show that ice concentrations were generally higher in or near downdrafts than in updrafts. Run 15.2 on Fig. 7 is a particularly clear example. It is also clear that while $N_{\text {Ice }}$ was higher in these downdrafts, $N_{\text {Round }}$ was also higher compared to updrafts. For much of the cloud's development, updraft regions contained greater concentrations of small liquid drops, while downdraft regions contained higher concentrations of larger hydrometeors, some of which were drizzle, and some of which were ice. The downdraft regions were, therefore, simply more mature regions of the cloud than the younger updraft regions. In order to have been detected in such downdrafts, the water contained in the drizzle drops must have travelled upwards in an updraft and grown into larger drops by collision-coalescence and condensation of water vapour, before reaching the downdraft. At some point along this trajectory, some fraction of the drizzle drops froze, and where this was due to interaction with a secondary-ice-forming process, they must have come into contact with pre-existing ice crystals.

The frozen drops in the downdrafts appeared more rimed and aged (i.e. less round) than those found in the updrafts. This means the frozen drops in the downdrafts were generally older, and are therefore more likely to have frozen nearer to cloud top. However, some recently frozen drops were recorded in runs 11.4-15.2, at measurement temperatures between -5 and $-10{ }^{\circ} \mathrm{C}$. The minimal amounts of riming on these particles means they must have frozen near the measurement level. The location at which the drops froze does not necessarily reveal the location at which the ice was produced. For example, a secondary ice splinter formed at $-6^{\circ} \mathrm{C}$ may be too small to observe in updrafts, but could have frozen a drizzle drop by the time it reached the same level in a downdraft. Conversely, if the splinter was formed near cloud top, it may travel in a downdraft (possibly in subsaturated conditions) to freeze a drop at the measurement level.

Perhaps the clearest consistent trend in the developing cloud measured in runs 10.3-16 was that drizzle and ice were generally well correlated with each other, but anti-correlated with cloud drops. In these developing mixed-phase regions of intermediate maturity (i.e. not young, but not yet glaciated), the development of ice and drizzle appeared to progress in parallel. Whatever ice multiplication processes were active, the majority of the early secondary ice went on to freeze drizzle drops, which formed the first large ice and precipitationsized particles. Furthermore, regardless of the ice production mechanism, the freezing of drizzle drops accelerates the growth of large ice by being large when they freeze, providing a shortcut through the growth phase.

\subsubsection{Secondary ice mechanisms}

There are several known secondary ice production mechanisms, each with different required conditions. $\mathrm{H}-\mathrm{M}$ is the most widely studied, and the best quantified, but requires specific conditions to be met. An alternative mechanism to gain recent attention is ice multiplication as supercooled drops freeze, either by fragmentation or spicule formation due to internal pressure. A third possible mechanism is the fragmentation of pre-existing ice particles by ice-ice collisions.

$\mathrm{H}-\mathrm{M}$ is active in the temperature range $-3>T>-8^{\circ} \mathrm{C}$, and requires the presence of graupel and cloud drops both smaller than $13 \mu \mathrm{m}$ and larger than $24 \mu \mathrm{m}$ in diameter (Mossop, 1976, 1978). Figure 1 shows a typical size distribution from a developing cloud at $T=-5^{\circ} \mathrm{C}$, measured during run 11.2. This cloud-drop size distribution was typical of liquid cloud sampled at this temperature. In non-glaciated cloud regions on run 11.2, droplets smaller than $13 \mu \mathrm{m}$ and larger than $24 \mu \mathrm{m}$ were ubiquitous, and this was also true during runs in the developing cloud discussed in Sect. 3.3. In terms of concentrations, in region I on run 11.2 there were around $100 \mathrm{~cm}^{-3}$ of droplets smaller than $13 \mu \mathrm{m}$ and $20 \mathrm{~cm}^{-3}$ larger than $24 \mu \mathrm{m}$ as measured by the CDP. Graupel was also found in all mixed-phase regions on run 11.2 and, once ice formation had begun, in the developing cloud discussed in Sect. 3.3. The images of graupel with different levels of riming also mean it is likely that riming was actively occurring during our observations.

The expected products of $\mathrm{H}-\mathrm{M}$ are large concentrations of columnar ice crystals, particularly in the temperature range $-3>T>-8^{\circ} \mathrm{C}$, but also at other temperatures when transported by up/downdrafts. Pristine or near-pristine columns were observed in concentrations up to several hundred per litre, both in mature cloud in runs at $T=-5^{\circ} \mathrm{C}$ and in updrafts at lower temperatures. In mature regions at $T=$ $-12{ }^{\circ} \mathrm{C}$, mixed-habit ice were found that must have spent part of their lives growing as columns, before moving to temperatures where plates are the ice crystal growth regime. Given that all the known conditions of $\mathrm{H}-\mathrm{M}$ were met in developing clouds, and the expected products of $\mathrm{H}-\mathrm{M}$ were found in mature clouds, it is likely that $\mathrm{H}-\mathrm{M}$ was operating.

Ice multiplication by freezing of supercooled drops has been postulated by several previous studies (e.g. Rangno and Hobbs, 2001; Rangno, 2008), but thus far quantification has been very limited. Possible mechanisms include shattering of drops into fragments, and the formation of spicules that eject gas bubble membranes that break off into ice fragments. Both processes may produce microscopic shards of ice, as well as large pieces that are recognisable as fragments of the shape of the original drop that froze. Most previous studies with observations of shattered drops have estimated droplet shattering may enhance ice concentrations by a modest amount (typically up to single-figure percentages) (Korolev et al., 2004; Rangno, 2008), though Lawson 
et al. (2015) recently presented some evidence that the process may enhance ice concentrations by multiple orders of magnitude over a timescale of minutes in tropical cumulus. Lawson et al. (2015) showed images of fragments of drops (i.e. frozen parts of the original spherical drop), and drops with protrusions that may be partway through spicule formation.

In our observations, we did not observe any drops that were obviously partway through spicule formation, and only two images of shattered drop fragments out of the thousands of images recorded by the 2DS and CPI. We note, however, that in mixed-phase clouds the detection efficiency of the CPI was poor, and many of the ice shapes recorded by the 2DS were somewhat irregular, making it difficult to determine their origin and history. Many of the frozen drops recorded by the 2DS were heavily rimed, meaning it is difficult to determine if any fragments may have broken off during freezing. The efficiency of the drop-freezing secondary ice production process is strongly linked to the concentration of drizzle- and rain-sized drops, as larger drops undergo greater fragmentation upon freezing (Lawson et al., 2015). The cloud base temperature in this case study was $\sim 11^{\circ} \mathrm{C}$ lower than those considered by Lawson et al. (2015), meaning the warm-rain process had less depth of cloud to generate large drops before reaching freezing temperatures. The cloud-drop number concentration here was also several times higher than those measured by Lawson et al. (2015). Consequently, the concentrations of larger drops entering ice-forming temperatures were much lower in this case, and the drop-freezing secondary ice mechanism would be expected to have less of an effect.

Modelling work by Lawson et al. (2015) suggested that the concentration of drops larger than $200 \mu \mathrm{m}$ in updrafts at $-6{ }^{\circ} \mathrm{C}$ was an indicator for whether significant ice enhancements by droplet fragmentation would occur. The mean concentrations of $N_{\text {Round }}>200 \mu \mathrm{m}$ in updrafts in runs 11.1, 11.4 , and 13 were $0,3.6$, and $0.9 \mathrm{~L}^{-1}$, respectively. Based on our observations alone we are not able to quantitatively assess the potential of droplet-freezing secondary ice formation to affect ice concentrations, but these numbers will serve as a reference point for microphysical simulations, which are beyond the scope of this paper. Using our observations of frozen drops and a comparison between our droplet size distributions and the observations and modelling work by Lawson et al. (2015), we are able to say that secondary ice formation associated with droplet freezing is likely to have been active in our case study, but to a lesser extent than in the updraft cores in tropical cumulus described by Lawson et al. (2015). The cooler cloud base in our case study means the drops were generally smaller when reaching freezing temperatures, and therefore less efficient at secondary ice production when freezing.

Fragmentation of ice during ice-ice collisions may be an additional secondary production mechanism. Yano and Phillips (2011) studied this process using a highly simplified conceptual model, and suggested it may rival H-M if suffi- cient concentrations of large supercooled drops were present to accelerate the formation of large graupel. The required conditions were the presence of millimetre-sized graupel, supercooled liquid, and pre-existing ice crystals, which were all present in our case study once ice formation had begun. However, the presence of large supercooled drops and graupel would also accelerate H-M (Phillips et al., 2001). Furthermore, the ice fragmentation rate used by Yano and Phillips (2011) was derived from laboratory studies using centimetre-sized balls of ice; other experiments using more realistically sized graupel have found that the collision velocity required is much larger than would be found in the atmosphere (Griggs and Choularton, 1986). Again, it is difficult to quantify what influence this process may have had on our case study, but given the lack of laboratory experiments confirming this process may occur in realistic conditions, it appears doubtful that it can have had a major influence on ice concentrations.

It seems most likely that the observed ice concentrations and habits described in Sect. 3 may be explained by a combination of $\mathrm{H}-\mathrm{M}$ and droplet-freezing multiplication, though the relative importance of each process is not clear, and will depend on time and location within the cloud. Both of these mechanisms may generate small ice fragments, which collide with and freeze larger drops due to their different fall speeds. Based on our observations, this appears to be the main pathway for production of precipitation-sized particles in the clouds, particularly in the intermediate stages of development. In contrast, much of the ice in the mature, glaciated regions was in the form of columns or mixed-habit ice, which had undergone significant growth by vapour deposition. We suggest these are likely to be small ice crystals that did not impact upon large drops and grew more slowly, so were left remaining once the frozen drops had precipitated out. The presence of columnar features in ice crystals in all the glaciated outflow regions suggests these particles were formed by an ice multiplication process that is most active at temperatures that columns form at, such as $\mathrm{H}-\mathrm{M}$.

It is clear that both $\mathrm{H}-\mathrm{M}$ and the droplet-freezing secondary ice mechanisms are intimately linked with the warmrain process. $\mathrm{H}-\mathrm{M}$ requires specific sizes of cloud drops and may be accelerated by graupel formed by frozen drops, and droplet-freezing multiplication is thought to be more prevalent when larger drops freeze. The temperature at which large concentrations of drizzle and raindrops form depends on the cloud base temperature, cloud-drop number concentration, and time-dependent factors such as updraft speed and cell lifetime. Conversely, the temperatures of the $0{ }^{\circ} \mathrm{C}$ level and $\mathrm{H}-\mathrm{M}$ zone are clearly fixed. In an atmosphere with a warmer cloud base, the concentrations of large drops entering and exiting the $\mathrm{H}-\mathrm{M}$ zone in updrafts and downdrafts would be higher, as would the fragmentation by the freezing of larger droplets. Conversely, a cooler cloud base would decrease the concentration of the larger drops. The warm-rain process, 
and its interaction with secondary ice processes, appears key to determining the timing and location of precipitation.

\section{Conclusions}

We have outlined the microphysical mechanisms that resulted in the development of precipitation and the glaciation of a line of cumulus that formed along the UK's southwest peninsula. The line formed in the early afternoon on a convergence line along the peninsula, and was similar to a quasistationary band of cloud that caused severe flooding to the village of Boscastle in August 2004. The line of clouds became longer and broader during the afternoon as a result of the combination of new cell formation and stratiform regions forming downwind of the convective cells. The glaciation process occurred in several stages:

- Primary ice nucleation formed the first ice particles in the initial cell. In agreement with Huang et al. (2008), the first ice and precipitation observed were frozen drizzle drops, rather than smaller ice grown by vapour deposition. The evidence therefore suggests that it was predominantly the larger drops that froze, rather than smaller, though this is not definitively clear.

- The concentration of ice particles increased slightly, either due to secondary ice formation occurring in the same thermal in which the supercooled raindrops froze, or increased primary ice nucleation as cloud top ascended, but significant enhancement of the ice crystal concentration was not observed until subsequent thermals ascended through the measurement region.

- Increasing ice concentrations well in excess of that expected from primary ice nucleation signalled the onset of secondary ice production, and the necessary conditions for both $\mathrm{H}-\mathrm{M}$ and droplet-freezing secondary ice processes were met. The majority of the initial secondary ice particles were observed as frozen drops. Small ice caused drizzle drops to freeze on contact, forming additional instant rimers. Larger drizzle and raindrops were preferentially frozen, as they were more likely to encounter splinters as a result of their larger size and fall speed.

- Frozen drizzle/raindrops and splinters were redistributed around the cloud by thermal circulation, and grew by riming and vapour deposition. Larger frozen drops formed millimetre-sized graupel, which added to the precipitation.

- Glaciated stratiform regions were formed as a result of the maturing of the clouds as they moved downwind. The concentration of cloud droplets will have been reduced by entrainment and conversion to ice, although the relative fractions of cloud drops lost to each of these effects are unknown. Ice remaining in the $\mathrm{H}-\mathrm{M}$ zone grew to form precipitation-sized aggregates of columns, but this took place more slowly than the freezing of supercooled drizzle. At higher altitudes the ice formed complex, mixed-habit ice particles, due to riming and growth by vapour deposition at temperatures with different dominant ice habits. Much of the ice measured in the mature, stratiform regions showed columnar features. This suggests that in the latter stages of ice formation, ice production is likely to have been dominated by a secondary ice mechanism that acts preferentially at temperatures where columns grow, such as $\mathrm{H}-\mathrm{M}$.

In the early stages of secondary ice development, the majority of precipitation-sized ice were frozen drizzle/raindrops, but their concentrations were much higher than the IN concentrations predicted by DeMott et al. (2010), suggesting they were liquid drops frozen by contact with small ice crystals. Frozen drops initially dominated concentrations of larger ice crystals, while small ice splinters required time to grow by vapour deposition. It is not clear what fraction of the small ice may have been produced by $\mathrm{H}-\mathrm{M}$ or ice multiplication associated with the freezing of the drops.

It is, however, clear that the warm-rain and secondary ice processes are intimately linked. $\mathrm{H}-\mathrm{M}$ requires cloud drops of a certain size, and is accelerated by the presence of freezing drizzle/rain to form instant rimers (Phillips et al., 2001). Ice multiplication processes associated with droplet freezing are thought to be more prolific for larger drops (Lawson et al., 2015). The young updrafts contained mostly cloud drops, whereas downdrafts and some updrafts at later stages contained fewer cloud drops but more ice and drizzle. Multiple thermals and cells emerged in a similar region over the measurement period, and the interaction between neighbouring cells and clouds can have a large impact on determining where and when different microphysical processes take place (Blyth and Latham, 1997). While it is not within the scope of this paper to make a full analysis of the interaction between dynamics and microphysics, this is an important topic for future modelling studies to investigate.

One of the major challenges in analysing observations of convective clouds is the rapid timescale over which changes can occur. By making multiple penetrations spaced a few minutes apart through the same cloud region, we have generated a data set that can be used to comment critically on model behaviour. For example, prototype versions of the Met Office Unified Model are being used to simulate this case at horizontal resolutions of 200 and $100 \mathrm{~m}$ (Leon et al., 2015). Such simulated cloud fields may be sampled with pseudo-aircraft penetrations such that the impact of changes to microphysical parameters or formulations can be identified (Abel and Shipway, 2007).

It has been known for some time that $\mathrm{H}-\mathrm{M}$ can operate in warm-base convective clouds spanning the $\mathrm{H}-\mathrm{M}$ temperature zone (e.g. Chisnell and Latham, 1976; Harris-Hobbs and 
Cooper, 1987; Blyth and Latham, 1993; Rangno and Hobbs, 2005) and that by providing the initial graupel the freezing of supercooled drizzle/raindrops formed by the warmrain process can advance the onset of $\mathrm{H}-\mathrm{M}$ (Phillips et al., 2001; Huang et al., 2008, 2011). The recent work by Lawson et al. (2015) suggests secondary ice production associated with droplet freezing may also be an important mechanism for cloud glaciation, but we are not able to fully quantify how much influence it had on the clouds in this study based on our observations alone. Our observations do show that the freezing of drizzle/raindrops is an important process that dominates the formation of large ice in the intermediate stages of cloud development. Based on the measured concentrations, we have postulated that the droplets must be frozen by contact with small ice particles, which may be produced by $\mathrm{H}-\mathrm{M}$, droplet-freezing secondary ice production, or some hitherto unknown or underestimated mechanism. Further investigation of this process would require the use of a cloud probe capable of quantifying small ice concentrations in clouds with droplet concentrations up to several hundred per cubic centimetre. As these frozen drops were the first precipitation observed, our results suggest that interactions between the warm-rain and secondary ice production processes are key to determining the timing and location of precipitation. 


\section{Appendix A}

\section{A1 OAP data processing}

OAP data processing was performed to derive size- and shape-segregated number concentrations as in Crosier et al. (2011, 2014). The OAP data processing software uses the raw image data to derive size-segregated concentrations. The sample volume was calculated using the measured airspeed and size-dependent sample area, as described by Heymsfield and Parrish (1978). Several criteria were used to quality assure the single-particle images. Particles with short interarrival times (IATs) are likely to be a result of ice shattering on the OAP inlet (Field et al., 2006), and those with IATs $<10^{-6}$ s were rejected. Anti-shatter tips (Korolev et al., 2011) were also used to minimise this issue. The use of a flat IAT threshold can result in inadequate removal of shattering artefacts (Korolev and Field, 2015), and/or inappropriate filtering of real particles. Using either no IAT threshold, or a threshold of $2 \times 10^{-6} \mathrm{~s}$, caused a $5-15 \%$ increase, or decrease, respectively, in the ice and round concentrations reported by the 2DS. The reported concentration of small drops was more affected, but this is not used in this analysis. Poorly imaged particles with $<80 \%$ of the pixels filled within the image perimeter, and streaks (images 1-pixel wide due to a faulty pixel in the OAP array) $>5$-pixels long, were also rejected.

The 2DS images were classified into different categories, shown in Table A1. Particles with area $<50$ pixels pixels were classed as small (S), and no shape analysis was performed on these particles, though they are likely to be liquid cloud drops. Those with area $\geq 50$ pixels are classified based on their circularity, and labelled low, medium, and high irregularity (LI, MI, and $\mathrm{HI}$, respectively). The threshold of 50 pixels is larger than that used by Crosier et al. (2011), but results in more reliable shape classification. In this analysis, 50 pixels corresponded to a mean size of $\sim 90 \mu \mathrm{m}$.

Visual inspection of the images showed that particles classed as LI were almost all round, and those classed as HI were almost all ice. Images in the MI category varied, and many were of indeterminate phase. The MI category was therefore divided proportionally between the LI and HI categories, to make new categories round and ice. Varying the circularity thresholds (in all categories concurrently) by \pm 0.05 caused a 5-20\% change in the ice and round concentrations reported by the $2 \mathrm{DS}$. It was not possible to perform shape analysis on images overlapping the edge of the array, and those with area $\geq 50$ pixels (EL) were assigned to either the round or ice categories on a run-by-run basis. In practice, the edge particles were rarely mixed phase, being either almost all round or almost all ice. The sample volume was calculated using the centre-in approach (Heymsfield and Parrish, 1978).
When combining the size distributions from the CDP, 2DS and CIP100 to calculate the parameter $R_{32}$, the all-accept category was used for the OAPs.

Due to the high cloud-drop concentrations encountered during COPE, the 2DS probe was occasionally overloaded with data, resulting in significant dead time. This dead time was calculated based on instrument diagnostics, and used to correct the instrument sample volume and therefore the derived number concentrations. In extreme cases, the dead time approached $90 \%$ of the sample time over a $1 \mathrm{~s}$ interval. The 2DS has two data channels measured by vertically and horizontally aligned detectors. We combined images from both channels to calculate an average concentration. This technique improves the counting statistics in low concentrations, as the large majority of particles are observed only on a single channel.

\section{A2 Ice production rate calculations}

Harris-Hobbs and Cooper (1987) detailed a method to calculate the ice production rate required to sustain a population of ice in a given size range, assuming a system in a steady state with a constant ice growth rate. The inferred ice production rate $\left(P_{0}\right)$ is calculated as

$P_{0}=\frac{\left[C\left(L_{2}\right)-C\left(L_{1}\right)\right]}{t_{21}}$,

where $C\left(L_{\mathrm{i}}\right)$ is the measured concentration of ice particles smaller than $L_{i}$, and $t_{21}$ is the time required for an ice crystal to grow via vapour deposition from size $L_{1}$ to $L_{2}$.

$t_{21}$ may be calculated using

$t_{21}=\frac{\left(L_{2}-L_{1}\right)}{G(T)}$,

where $G(T)$ is the ice growth rate as a function of temperature.

We use values of $G(T)$ taken from Ryan et al. (1976), using the measurement temperature. The calculation assumes ice crystal growth at water saturation, which is valid in mixed-phase clouds, but does not take into account growth by riming. Ryan et al. (1976) provided values of $G(T)$ for pristine columns and plates, but the appropriate crystal growth rates are unclear for irregular ice such as graupel. We therefore only apply the calculation in regions where columns comprise the large majority ice crystals. The accuracy of the derived values of $P_{0}$ is difficult to quantify, but is likely to be within an order of magnitude. For this analysis, we calculate $P_{0}$ using the cumulative ice size distribution smaller than $100 \mu \mathrm{m}$ and smaller than $150 \mu \mathrm{m}$. The ice concentrations were calculated as described in Appendix A1. 
Table A1. Summary of 2DS data products. Level 1 refers to standard products output by the data processing software, and are mutually exclusive (i.e. any accepted particle falls into only one level 1 category). Level 2 products are specific to COPE. Particles with IAT $<1 \mu$ s were excluded in all categories to minimise shattering artefacts.

\begin{tabular}{|c|c|c|c|c|}
\hline \multicolumn{5}{|l|}{ 2DS data products } \\
\hline \multicolumn{5}{|l|}{ Level 1} \\
\hline Category & Abbreviation & Area (pixels) & Circularity & Edge rejection \\
\hline Small & S & $<50$ & All & On \\
\hline Low irregularity & LI & $\geq 50$ & $<1.2$ & On \\
\hline Medium irregularity & MI & $\geq 50$ & $1.2-1.4$ & On \\
\hline High irregularity & HI & $\geq 50$ & $>1.4$ & On \\
\hline Edge small & $\mathrm{ES}$ & $<50$ & All & Only edge \\
\hline Edge large & EL & $\geq 50$ & All & Only edge \\
\hline \multicolumn{5}{|l|}{ Level 2} \\
\hline Category & Abbreviation & \multicolumn{3}{|l|}{ Calculation } \\
\hline Large enough to be classified by shape & D90 & \multicolumn{3}{|c|}{$\mathrm{LI}+\mathrm{MI}+\mathrm{HI}+\mathrm{EL}$} \\
\hline Round & - & \multicolumn{3}{|c|}{$\mathrm{LI}+\mathrm{MI} \times \mathrm{LI} /(\mathrm{LI}+\mathrm{HI})[+\mathrm{EL}]^{*}$} \\
\hline Ice & - & \multicolumn{3}{|c|}{$\mathrm{LI}+\mathrm{MI} \times \mathrm{HI} /(\mathrm{LI}+\mathrm{HI})[+\mathrm{EL}]^{*}$} \\
\hline All-accept & - & \multicolumn{3}{|c|}{$\mathrm{S}+\mathrm{LI}+\mathrm{MI}+\mathrm{HI}+\mathrm{ES}+\mathrm{EL}$} \\
\hline
\end{tabular}

* EL particles were assigned to either the round or ice categories by visually examining the images on a run-by-run basis. 
Acknowledgements. The authors wish to thank all those involved in COPE. The BAe-146-301 Atmospheric Research Aircraft was flown by Directflight Ltd. and managed by the Facility for Airborne Atmospheric Measurements (FAAM), which is a joint entity of the Natural Environment Research Council (NERC) and the Met Office. Processed data are available from the British Atmospheric Data Centre. Raw data are archived at the University of Manchester and available on request. COPE was supported by NERC under grant numbers NE/J022594/1 and NE/J023507/1, and the Met Office funded the operation of the BAe-146 FAAM aircraft. The US investigators were funded by NSF grant AGS-1230203, and the UWKA was funded by NSF grant ATM-0832637. We would also like to thank David Leon for his technical comments. Finally, we thank the editor and the three anonymous reviewers, whose detailed comments helped improve the scientific quality of the manuscript.

Edited by: O. Möhler

\section{References}

Abel, S. J. and Shipway, B. J.: A comparison of cloud-resolving model simulations of trade wind cumulus with aircraft observations taken during RICO, Q. J. Roy. Meteor. Soc., 133, 781-794, doi:10.1002/qj.55, 2007.

Baumgardner, D., Jonsson, H., Dawson, W., O'Connor, D., and Newton, R.: The cloud, aerosol and precipitation spectrometer: a new instrument for cloud investigations, Atmos. Res., 59-60, 251-264, doi:10.1016/S0169-8095(01)00119-3, 2001.

Baumgardner, D., Popovicheva, O., Allan, J., Bernardoni, V., Cao, J., Cavalli, F., Cozic, J., Diapouli, E., Eleftheriadis, K., Genberg, P. J., Gonzalez, C., Gysel, M., John, A., Kirchstetter, T. W., Kuhlbusch, T. A. J., Laborde, M., Lack, D., Müller, T., Niessner, R., Petzold, A., Piazzalunga, A., Putaud, J. P., Schwarz, J., Sheridan, P., Subramanian, R., Swietlicki, E., Valli, G., Vecchi, R., and Viana, M.: Soot reference materials for instrument calibration and intercomparisons: a workshop summary with recommendations, Atmos. Meas. Tech., 5, 1869-1887, doi:10.5194/amt-51869-2012, 2012.

Bennett, L. J., Browning, K. A., Blyth, A. M., Parker, D. J., and Clark, P. A.: A review of the initiation of precipitating convection in the United Kingdom, Q. J. Roy. Meteor. Soc., 132, 1001-1020, doi:10.1256/qj.05.54, 2006.

Beswick, K. M., Gallagher, M. W., Webb, A. R., Norton, E. G., and Perry, F.: Application of the Aventech AIMMS20AQ airborne probe for turbulence measurements during the Convective Storm Initiation Project, Atmos. Chem. Phys., 8, 5449-5463, doi:10.5194/acp-8-5449-2008, 2008.

Blyth, A. M. and Latham, J.: Development of ice and precipitation in New Mexican summertime cumulus clouds, Q. J. Roy. Meteor. Soc., 119, 91-120, doi:10.1002/qj.49711950905, 1993.

Blyth, A. M. and Latham, J.: A multi-thermal model of cumulus glaciation via the hallett-Mossop process, Q. J. Roy. Meteor. Soc., 123, 1185-1198, doi:10.1002/qj.49712354104, 1997.

Blyth, A. M., Lasher-Trapp, S. G., and Cooper, W. A.: A study of thermals in cumulus clouds, Q. J. Roy. Meteor. Soc., 131, 11711190, doi:10.1256/qj.03.180, 2005.
Blyth, A. M., Bennett, L. J., and Collier, C. G.: High-resolution observations of precipitation from cumulonimbus clouds, Meteorol. Appl., 22, 75-89, doi:10.1002/met.1492, 2015.

Browning, K. A., Morcrette, C. J., Nicol, J., Blyth, A. M., Bennett, L. J., Brooks, B. J., Marsham, J., Mobbs, S. D., Parker, D. J., Perry, F., Clark, P. A., Ballard, S. P., Dixon, M. A., Forbes, R. M., Lean, H. W., Li, Z., Roberts, N. M., Corsmeier, U., Barthlott, C., Deny, B., Kalthoff, N., Khodayar, S., Kohler, M., Kottmeier, C., Kraut, S., Kunz, M., Lenfant, J., Wieser, A., Agnew, J. L., Bamber, D., McGregor, J., Beswick, K. M., Gray, M. D., Norton, E., Ricketts, H. M. A., Russell, A., Vaughan, G., Webb, A. R., Bitter, M., Feuerle, T., Hankers, R., Schulz, H., Bozier, K. E., Collier, C. G., Davies, F., Gaffard, C., Hewison, T. J., Ladd, D. N., Slack, E. C., Waight, J., Ramatschi, M., Wareing, D. P., and Watson, R. J.: The Convective Storm Initiation Project, B. Am. Meteorol. Soc., 88, 1939-1955, doi:10.1175/BAMS-88-12-1939, 2007.

Burpee, R. W.: Peninsula-Scale Convergence in the South Florida Sea Breeze, Mon. Weather Rev., 107, 852-860, doi:10.1175/1520-0493(1979) 107<0852:PSCITS>2.0.CO;2, 1979.

Canagaratna, M. R., Jayne, J. T., Jimenez, J. L., Allan, J. D., Alfarra, M. R., Zhang, Q., Onasch, T. B., Drewnick, F., Coe, H., Middlebrook, A., Delia, A., Williams, L. R., Trimborn, A. M., Northway, M. J., DeCarlo, P. F., Kolb, C. E., Davidovits, P., and Worsnop, D. R.: Chemical and microphysical characterization of ambient aerosols with the aerodyne aerosol mass spectrometer., Mass Spectrom. Rev., 26, 185-222, doi:10.1002/mas.20115, 2007.

Chisnell, R. F. and Latham, J.: Ice particle multiplication in cumulus clouds, Q. J. Roy. Meteor. Soc., 102, 133-156, doi:10.1002/qj.49710243111, 1976.

Connolly, P. J., Flynn, M. J., Ulanowski, Z., Choularton, T. W., Gallagher, M. W., and Bower, K. N.: Calibration of the Cloud Particle Imager Probes Using Calibration Beads and Ice Crystal Analogs: The Depth of Field, J. Atmos. Ocean. Tech., 24, 18601879, doi:10.1175/JTECH2096.1, 2007.

Cornwall Council: Preliminary Flood Risk Assessment Report, available at: http://www.cornwall.gov.uk/environment-andplanning/countryside/estuaries-rivers-and-wetlands/flood-

risk/preliminary-flood-risk-assessment-2011/ (last access: 14 January 2016), 2011.

Crawford, I., Bower, K. N., Choularton, T. W., Dearden, C., Crosier, J., Westbrook, C., Capes, G., Coe, H., Connolly, P. J., Dorsey, J. R., Gallagher, M. W., Williams, P., Trembath, J., Cui, Z., and Blyth, A.: Ice formation and development in aged, wintertime cumulus over the UK: observations and modelling, Atmos. Chem. Phys., 12, 4963-4985, doi:10.5194/acp-12-4963-2012, 2012.

Crosier, J., Bower, K. N., Choularton, T. W., Westbrook, C. D., Connolly, P. J., Cui, Z. Q., Crawford, I. P., Capes, G. L., Coe, H., Dorsey, J. R., Williams, P. I., Illingworth, A. J., Gallagher, M. W., and Blyth, A. M.: Observations of ice multiplication in a weakly convective cell embedded in supercooled mid-level stratus, Atmos. Chem. Phys., 11, 257-273, doi:10.5194/acp-11-257-2011, 2011.

Crosier, J., Choularton, T. W., Westbrook, C. D., Blyth, A. M., Bower, K. N., Connolly, P. J., Dearden, C., Gallagher, M. W., Cui, Z., and Nicol, J. C.: Microphysical properties of cold frontal rainbands, Q. J. Roy. Meteor. Soc., 140, 1257-1268, doi:10.1002/qj.2206, 2014. 
Dasari, H. P. and Salgado, R.: Numerical modelling of heavy rainfall event over Madeira Island in Portugal: sensitivity to different micro physical processes, Meteorol. Appl., 22, 113-127, doi:10.1002/met.1375, 2015.

DeMott, P. J., Prenni, A. J., Liu, X., Kreidenweis, S. M., Petters, M. D., Twohy, C. H., Richardson, M. S., Eidhammer, T., and Rogers, D. C.: Predicting global atmospheric ice nuclei distributions and their impacts on climate, P. Natl. Acad. Sci. USA, 107, 11217-11222, doi:10.1073/pnas.0910818107, 2010.

Drewnick, F., Hings, S. S., DeCarlo, P., Jayne, J. T., Gonin, M., Fuhrer, K., Weimer, S., Jimenez, J. L., Demerjian, K. L., Borrmann, S., and Worsnop, D. R.: A New Time-of-Flight Aerosol Mass Spectrometer (TOF-AMS)- Instrument Description and First Field Deployment, Aerosol Sci. Tech., 39, 637658, doi:10.1080/02786820500182040, 2005.

Environment Agency: Flooding in England: A National Assessment of Flood Risk, Tech. rep., Environment Agency, Bristol, UK, 2009.

Field, P. R., Heymsfield, A. J., and Bansemer, A.: Shattering and Particle Interarrival Times Measured by Optical Array Probes in Ice Clouds, J. Atmos. Ocean. Tech., 23, 1357-1371, doi:10.1175/JTECH1922.1, 2006.

French, J. R., Vali, G., and Kelly, R. D.: Evolution of small cumulus clouds in Florida: observations of pulsating growth, Atmos. Res., 52, 143-165, doi:10.1016/S0169-8095(99)00024-1, 1999.

Golding, B. (Ed.): Boscastle and north Cornwall post flood event study - meteorological analysis of the conditions leading to flooding on 16 August 2004, 459, Met Office, available at: http: //www.metoffice.gov.uk/media/pdf/m/g/FRTR459.pdf (last access: 14 January 2016), 2005.

Golding, B., Clark, P., and May, B.: The Boscastle flood: Meteorological analysis of the conditions leading to flooding on $16 \mathrm{Au}-$ gust 2004, Weather, 60, 230-235, doi:10.1256/wea.71.05, 2005.

Griggs, D. J. and Choularton, T. W.: A laboratory study of secondary ice particle production by the fragmentation of rime and vapour-grown ice crystals, Q. J. Roy. Meteor. Soc., 112, 149163, doi:10.1002/qj.49711247109, 1986.

Hallett, J. and Mossop, S. C.: Production of secondary ice particles during the riming process, Nature, 249, 26-28, doi:10.1038/249026a0, 1974.

Hand, W. H., Fox, N. I., and Collier, C. G.: A study of twentieth-century extreme rainfall events in the United Kingdom with implications for forecasting, Meteorol. Appl., 11, 15-31, doi:10.1017/S1350482703001117, 2004.

Harris-Hobbs, R. L. and Cooper, W. A.: Field Evidence Supporting Quantitative Predictions of Secondary Ice Production Rates, J. Atmos. Sci., 44, 1071-1082, doi:10.1175/15200469(1987)044<1071:FESQPO>2.0.CO;2, 1987.

Hering, S. V., Stolzenburg, M. R., Quant, F. R., Oberreit, D. R., and Keady, P. B.: A Laminar-Flow, Water-Based Condensation Particle Counter (WCPC), Aerosol Sci. Tech., 39, 659-672, doi:10.1080/02786820500182123, 2005.

Heymsfield, A. J. and Parrish, J. L.: A Computational Technique for Increasing the Effective Sampling Volume of the PMS Two-Dimensional Particle Size Spectrometer, J. Appl. Meteorol., 17, 1566-1572, doi:10.1175/15200450(1978)017<1566:ACTFIT>2.0.CO;2, 1978.

Huang, X. F., Gao, R. S., Schwarz, J. P., He, L. Y., Fahey, D. W., Watts, L. A., McComiskey, A., Cooper, O. R., Sun, T. L., Zeng,
L. W., Hu, M., and Zhang, Y. H.: Black carbon measurements in the Pearl River Delta region of China, J. Geophys. Res.-Atmos., 116, D12208, doi:10.1029/2010jd014933, 2011.

Huang, Y., Blyth, A. M., Brown, P. R. A., Choularton, T. W., Connolly, P., Gadian, A. M., Jones, H., Latham, J., Cui, Z., and Carslaw, K.: The development of ice in a cumulus cloud over southwest England, New J. Phys., 10, 105021, doi:10.1088/1367-2630/10/10/105021, 2008.

Koenig, L. R.: The Glaciating Behavior of Small Cumulonimbus Clouds, J. Atmos. Sci., 20, 29-47, doi:10.1175/15200469(1963)020<0029:TGBOSC>2.0.CO;2, 1963.

Korolev, A. and Field, P. R.: Assessment of the performance of the inter-arrival time algorithm to identify ice shattering artifacts in cloud particle probe measurements, Atmos. Meas. Tech., 8, 761777, doi:10.5194/amt-8-761-2015, 2015.

Korolev, A. and Sussman, B.: A Technique for Habit Classification of Cloud Particles, J. Atmos. Ocean. Tech., 17, 1048-1057, doi:10.1175/1520-0426(2000)017<1048:ATFHCO>2.0.CO;2, 2000.

Korolev, A. V., Bailey, M. P., Hallett, J., and Isaac, G. A.: Laboratory and In Situ Observation of Deposition Growth of Frozen Drops, J. Appl. Meteorol., 43, 612-622, doi:10.1175/15200450(2004)043<0612:LAISOO>2.0.CO;2, 2004.

Korolev, A. V., Emery, E. F., Strapp, J. W., Cober, S. G., Isaac, G. A., Wasey, M., and Marcotte, D.: Small Ice Particles in Tropospheric Clouds: Fact or Artifact? Airborne Icing Instrumentation Evaluation Experiment, B. Am. Meteorol. Soc., 92, 967973, doi:10.1175/2010BAMS3141.1, 2011.

Laborde, M., Schnaiter, M., Linke, C., Saathoff, H., Naumann, K.H., Möhler, O., Berlenz, S., Wagner, U., Taylor, J. W., Liu, D., Flynn, M., Allan, J. D., Coe, H., Heimerl, K., Dahlkötter, F., Weinzierl, B., Wollny, A. G., Zanatta, M., Cozic, J., Laj, P., Hitzenberger, R., Schwarz, J. P., and Gysel, M.: Single Particle Soot Photometer intercomparison at the AIDA chamber, Atmos. Meas. Tech., 5, 3077-3097, doi:10.5194/amt-5-3077-2012, 2012.

Lance, S.: Coincidence Errors in a Cloud Droplet Probe (CDP) and a Cloud and Aerosol Spectrometer (CAS), and the Improved Performance of a Modified CDP, J. Atmos. Ocean. Tech., 29, 15321541, doi:10.1175/JTECH-D-11-00208.1, 2012.

Lance, S., Brock, C. A., Rogers, D., and Gordon, J. A.: Water droplet calibration of the Cloud Droplet Probe (CDP) and inflight performance in liquid, ice and mixed-phase clouds during ARCPAC, Atmos. Meas. Tech., 3, 1683-1706, doi:10.5194/amt3-1683-2010, 2010.

Lawson, R. P. and Cooper, W. A.: Performance of Some Airborne Thermometers in Clouds, J. Atmos. Ocean. Tech., 7, 480-494, doi:10.1175/1520-0426(1990)007<0480:POSATI>2.0.CO;2, 1990.

Lawson, R. P., O'Connor, D., Zmarzly, P., Weaver, K., Baker, B., Mo, Q., and Jonsson, H.: The 2D-S (Stereo) Probe: Design and Preliminary Tests of a New Airborne, High-Speed, HighResolution Particle Imaging Probe, J. Atmos. Ocean. Tech., 23, 1462-1477, doi:10.1175/JTECH1927.1, 2006.

Lawson, R. P., Woods, S., and Morrison, H.: The Microphysics of Ice and Precipitation Development in Tropical Cumulus Clouds, J. Atmos. Sci., 72, 2429-2445, doi:10.1175/JAS-D-14-0274.1, 2015. 
Leon, D., French, J. R., Lasher-Trapp, S. G., Blyth, A. M., Abel, S. J., Ballard, S., Bennett, L. J., Bower, K. N., Brooks, B. J., Brown, P., Choularton, T. W., Clark, P., Collier, C. G., Crosier, J., Cui, Z., Dufton, D., Eagle, C., Flynn, M. J., Gallagher, M., Hanley, K. E., Huang, Y., Kitchen, M., Korolev, A., Lean, H. W., Liu, Z., Marsham, J., Moser, D., Nichol, J., Norton, E., Plummer, D., Price, J., Ricketts, H. M. A., Taylor, J. W., Roberts, N. M., and Williams, P. I.: The COnvective Precipitation Experiment (COPE): Investigating the origins of heavy precipitation in the southwestern UK, B. Am. Meteorol. Soc., accepted, 2015.

Loftus, A. and Cotton, W.: A triple-moment hail bulk microphysics scheme. Part II: Verification and comparison with two-moment bulk microphysics, Atmos. Res., 150, 97-128, doi:10.1016/j.atmosres.2014.07.016, 2014.

Mangia, C., Martano, P., Miglietta, M. M., Morabito, A., and Tanzarella, A.: Modelling local winds over the Salento peninsula, Meteorol. Appl., 11, 231-244, doi:10.1017/S135048270400132X, 2004.

Met Office: Met Office Rain Radar Data from the NIMROD System, available at: http://catalogue.ceda.ac.uk/uuid/ 82adec1f896af6169112d09cc1174499 (last access: 14 January 2016), 2003.

Mossop, S. C.: Production of secondary ice particles during the growth of graupel by riming, Q. J. Roy. Meteor. Soc., 102, 45-57, doi:10.1002/qj.49710243104, 1976.

Mossop, S. C.: The influence of drop size distribution on the production of secondary ice particles during graupel growth, Q. J. Roy. Meteor. Soc., 104, 323-330, doi:10.1002/qj.49710444007, 1978.

Phillips, V. T. J., Blyth, A. M., Brown, P. R. A., Choularton, T. W., and Latham, J.: The glaciation of a cumulus cloud over New Mexico, Q. J. Roy. Meteor. Soc., 127, 1513-1534, doi:10.1002/qj.49712757503, 2001.

Rangno, A. L.: Fragmentation of Freezing Drops in Shallow Maritime Frontal Clouds, J. Atmos. Sci., 65, 1455-1466, doi:10.1175/2007JAS2295.1, 2008.

Rangno, A. L. and Hobbs, P. V.: Ice particles in stratiform clouds in the Arctic and possible mechanisms for the production of high ice concentrations, J. Geophys. Res., 106, 15065, doi:10.1029/2000JD900286, 2001.

Rangno, A. L. and Hobbs, P. V.: Microstructures and precipitation development in cumulus and small cumulonimbus clouds over the warm pool of the tropical Pacific Ocean, Q. J. Roy. Meteor. Soc., 131, 639-673, doi:10.1256/qj.04.13, 2005.
Rosenberg, P. D., Dean, A. R., Williams, P. I., Dorsey, J. R., Minikin, A., Pickering, M. A., and Petzold, A.: Particle sizing calibration with refractive index correction for light scattering optical particle counters and impacts upon PCASP and CDP data collected during the Fennec campaign, Atmos. Meas. Tech., 5, 1147-1163, doi:10.5194/amt-5-1147-2012, 2012.

Ryan, B. F., Wishart, E. R., and Shaw, D. E.: The Growth Rates and Densities of Ice Crystals between $-3{ }^{\circ} \mathrm{C}$ and $-21^{\circ} \mathrm{C}$, J. Atmos. Sci., 33, 842-850, doi:10.1175/15200469(1976)033<0842:TGRADO>2.0.CO;2, 1976.

Schwarz, J. P., Spackman, J. R., Gao, R. S., Perring, A. E., Cross, E., Onasch, T. B., Ahern, A., Wrobel, W., Davidovits, P., Olfert, J., Dubey, M. K., Mazzoleni, C., and Fahey, D. W.: The Detection Efficiency of the Single Particle Soot Photometer, Aerosol Sci. Tech., 44, 612-628, doi:10.1080/02786826.2010.481298, 2010.

Stein, T. H. M., Hogan, R. J., Clark, P. A., Halliwell, C. E., Hanley, K. E., Lean, H. W., Nicol, J. C., and Plant, R. S.: The DYMECS project: A statistical approach for the evaluation of convective storms in high-resolution NWP models, B. Am. Meteorol. Soc., 96, 939-951, doi:10.1175/BAMS-D-13-00279.1, 2015.

Stephens, M., Turner, N., and Sandberg, J.: Particle Identification by Laser-Induced Incandescence in a Solid-State Laser Cavity, Appl. Opt., 42, 3726-3736, doi:10.1364/AO.42.003726, 2003.

Sun, J., Ariya, P. A., Leighton, H. G., and Yau, M. K.: Mystery of ice multiplication in warm-based precipitating shallow cumulus clouds, Geophys. Res. Lett., 37, L10802, doi:10.1029/2010GL042440, 2010.

Wang, Y. and Geerts, B.: Estimating the Evaporative Cooling Bias of an Airborne Reverse Flow Thermometer, J. Atmos. Ocean. Tech., 26, 3-21, doi:10.1175/2008JTECHA1127.1, 2009.

Wang, Z., French, J., Vali, G., Wechsler, P., Haimov, S., Rodi, A., Deng, M., Leon, D., Snider, J., Peng, L., and Pazmany, A. L.: Single Aircraft Integration of Remote Sensing and In Situ Sampling for the Study of Cloud Microphysics and Dynamics, B. Am. Meteorol. Soc., 93, 653-668, doi:10.1175/BAMS-D-1100044.1, 2012.

Warren, R. A., Kirshbaum, D. J., Plant, R. S., and Lean, H. W.: A "Boscastle-type" quasi-stationary convective system over the UK Southwest Peninsula, Q. J. Roy. Meteor. Soc., 140, 240-257, doi:10.1002/qj.2124, 2014.

Yano, J.-I. and Phillips, V. T. J.: Ice-Ice Collisions: An Ice Multiplication Process in Atmospheric Clouds, J. Atmos. Sci., 68, 322-333, doi:10.1175/2010JAS3607.1, 2011. 